\title{
Meditation and the brain in health and disease
}

Kieran C. R. Fox ${ }^{\mathrm{a}, \mathrm{b}, *}$ and B. Rael Cahn ${ }^{\mathrm{c}, \mathrm{d}}$

a Department of Neurology and Neurological Sciences, Stanford University, Stanford, CA, U.S.A.

b School of Medicine, Stanford University, Stanford, CA, U.S.A.

c Department of Psychiatry and Behavioral Sciences, University of Southern California, Los Angeles, CA, U.S.A.

${ }^{d}$ Brain and Creativity Institute, University of Southern California, Los Angeles, CA, U.S.A.

* To whom correspondence may be addressed: kcrfox@stanford.edu 


\begin{abstract}
The aim of this chapter is to provide an accessible introduction to the neuroscience of meditation. First, we review studies examining the relationship between meditation and alterations in the structure of the brain's grey and white matter (so-called morphometric neuroimaging). Next, we discuss findings from functional neuroimaging methods, such as functional magnetic resonance imaging (fMRI) and positron emission tomography (PET) scans, and what they have taught us about the brain's patterns of activity during different forms of meditation, how meditation alters the brain's response to various tasks and experiences, and how the expertise of long-term meditators might be harnessed to help us explore subtle aspects of human cognition. Third, we review electrophysiological methods of measuring brain activity during meditation, such as electroencephalography (EEG), and how these findings relate to what we have learned from morphometric and functional neuroimaging. Finally, we discuss the implications of this research and of meditation more generally for brain health and psychological well-being. Specifically, we focus on how meditation might ameliorate the deficits related to cognitive aging, as well as help ameliorate the symptoms and underlying neural substrates associated with neurodegenerative and psychiatric disease.
\end{abstract}

Keywords: meditation; brain; neuroplasticity; contemplative neuroscience; neuroimaging; brain health; 


\section{Introduction}

Meditation - the mysterious capacity of the human mind to turn back upon and contemplate itself - has been developed, debated, practiced, and persecuted for thousands of years. Like music, language, and art, it seems to be a uniquely human quality, and likewise, its origins are lost in legend (Eliade, 1964; Johnson, 1982; Wynne, 2007). Despite being part of our most ancient human heritage, serious investigation of meditation's neural basis began only a few decades ago. The nascent fields now being referred to as 'contemplative science' and 'contemplative neuroscience' (Thompson, 2009) are very much phenomena of the $21^{\text {st }}$ century, with an unprecedented acceleration in meditation research in recent years (Van Dam, van Vugt, Vago, Schmalzl, Saron, Olendzki, Meissner, Lazar, Kerr, et al., 2018) - in contrast to the slow and haphazard accrual of knowledge throughout the $20^{\text {th }}$ century (Cahn $\&$ Polich, 2006).

A truly rigorous neuroscience of meditation still lies in the future (Cahn \& Polich, 2006; K.C.R. Fox, Dixon, et al., 2016; K.C.R. Fox et al., 2014; Van Dam, van Vugt, Vago, Schmalzl, Saron, Olendzki, Meissner, Lazar, Gorchov, et al., 2018; Van Dam, van Vugt, Vago, Schmalzl, Saron, Olendzki, Meissner, Lazar, Kerr, et al., 2018), but nonetheless, enormous strides have been taken since scientists first patched electrodes onto the heads of people practicing various forms of meditation in the 1950s and 1960s (Bagchi \& Wenger, 1957; Das \& Gastaut, 1955; Kasamatsu \& Hirai, 1966; Kasamatsu et al., 1957). Since these early studies, virtually every tool available for investigating the structure and function of the human brain has been employed at one time or another to shed some light on the neural correlates of long-term practice of, and short-term training in, meditation. 
Meditation is one of those terms that it seems necessary, yet impossible, to properly define; meditation has meant, and continues to mean, so many things to so many groups that any definition is bound to be selective and of only limited generalizability. Here we define meditation as a family of mental training practices aimed at monitoring and regulating attention, perception, emotion, and physiology (e.g., respiration or level of arousal). This relatively bland definition, used before both by us (Cahn \& Polich, 2006; K.C.R. Fox, Dixon, et al., 2016; K.C.R. Fox et al., 2014) and by other researchers (A. Lutz, Slagter, Dunne, \& Davidson, 2008; Y.-Y. Tang, Hölzel, \& Posner, 2015), has the merits of being non-sectarian (it encompasses practices from many different religious and ethnic groups) and of emphasizing aspects of meditation that are measurable (i.e., those that can be investigated with contemporary neuroscientific and physiological methods, and are therefore admissible in the court of scientific study). On the other hand, such a definition leaves out components that are considered crucial by virtually every contemplative tradition, especially their metaphysical goals and claims (most practices proffer some central insight(s) into the nature of reality and/or the self) and their soteriological aspects (most practices are explicitly aimed at enlightenment (nirvana), liberation (moksha), or some related state or transformation). Defining meditation as mental training therefore encompasses most of the qualities measurable by, and currently of interest to, scientists, but leaves aside those aspects neuroscientists are unable, or at least not yet able, to investigate (although see (Davis \& Vago, 2013).

Most scientific research to date has focused on Buddhist-derived meditation and mindfulness practices (Y.-Y. Tang et al., 2015; Van Dam, van Vugt, Vago, Schmalzl, Saron, Olendzki, Meissner, Lazar, Kerr, et al., 2018). Although there is growing neuroscientific 
work on Christian prayer (Neubauer, 2014; Newberg, Pourdehnad, Alavi, \& d'Aquili, 2003; Schjødt, Stødkilde-Jørgensen, Geertz, \& Roepstorff, 2008), yogic and Hindu meditation practices (Kakigi et al., 2005; Kalyani et al., 2011; Kjaer et al., 2002), and even related ecstatic shamanic techniques (Hove et al., 2015), here we also focus largely on Buddhistderived techniques, including secular mindfulness practices, because they are by far the best studied, therefore offering the firmest ground on which to base conclusions and inferences.

The goal of this chapter is to provide a succinct overview of what we have learned to date about the multifaceted relationship between meditation and the brain in both health and disease. The subsequent sections offer a variety of perspectives on these relationships. First, we review studies examining the relationship between meditation and alterations in the structure of the brain's grey and white matter (so-called morphometric neuroimaging). Next, we discuss findings from functional neuroimaging methods, such as functional magnetic resonance imaging (fMRI) and positron emission tomography (PET) scans, and what they have taught us about the brain's patterns of activity during different forms of meditation, how meditation alters the brain's response to various tasks and experiences, and how the expertise of long-term meditators might be harnessed to help us explore subtle aspects of human cognition. Third, we review electrophysiological methods of measuring brain activity during meditation, such as electroencephalography (EEG), and how these findings relate to what we have learned from morphometric and functional neuroimaging. Finally, we discuss the implications of this research and of meditation more generally for brain health and psychological well-being. Specifically, we focus on how meditation might ameliorate the deficits related to cognitive aging, as well as help 
Meditation and the brain

ameliorate the symptoms and underlying neural abnormalities associated with neurodegenerative and psychiatric disease. 


\section{Meditation and brain structure}

That the practice of new skills and learning of new information effects changes in the fine-scale structure of the brain is no longer controversial (Caroni, Chowdhury, \& Lahr, 2014). This learning-dependent neuroplasticity is generally agreed to provide the substratum for retaining new knowledge, memories, and skills. By employing animal models and in vitro investigations of brain tissue, neuroscientists have been able to develop an increasingly refined model of the synaptic and molecular changes underlying neuroplastic changes, and how they relate to learning (Caroni et al., 2014; Marx \& Gilon, 2012). In humans, however, studies of these microscale changes generally are not feasible, so research has instead relied upon an ever-expanding suite of methods that can assess the shape, density, and composition of the brain's structure in vivo - tools collectively known as morphometric neuroimaging (May \& Gaser, 2006; Zatorre, Fields, \& Johansen-Berg, 2012).

Early studies using these methods showed that people with high levels of expertise, for instance highly-trained or professional musicians, showed greater grey matter volume (compared to non-musician control subjects) in parts of the brain crucial for fine motor control and auditory processing (Gaser \& Schlaug, 2003; Schneider et al., 2002). This research suggested that training had induced the changes, but a major limitation was that the musicians had not been investigated longitudinally - i.e., the researchers had not studied their brains both before and after musical training, to establish that training itself had been the cause. A glaring and plausible alternative explanation was that people with greater manual dexterity and sensitivity - perhaps instantiated in the brain in measurable differences in grey matter in these motor regions - were likewise those who excelled at, and therefore persisted in, their musical endeavors. In this case, differential grey matter 
density in motor cortices would be the cause, not the consequence, of long-term musical practice. As we shall see, this same concern remains a major issue in studies of the brains of long-term meditation practitioners. This section explores (i) whether meditation is indeed associated with altered brain structure; (ii) whether different findings have been reported from the study of long-term practitioners as compared to those undergoing short-term meditation training; and (iii) some of the methodological concerns related to this research.

Is meditation associated with altered brain structure?

Dozens of studies have now used morphometric neuroimaging to examine whether long-term practice of, or short-term training in, meditation is associated with altered brain structure (K.C.R. Fox et al., 2014). Because of the diversity of methods used and the hundreds of individual findings reported to date, it is difficult to interpret this rapidly growing body of work and understand whether or not there are consistent trends among all these findings. In an effort to synthesize this research, Fox and colleagues (2014) conducted a systematic review and meta-analysis of all morphometric neuroimaging studies of meditation (a meta-analysis of neuroimaging studies concatenates data from many independent investigations, seeking for consistency and replicability among the results (Wager, Lindquist, \& Kaplan, 2007; Wager, Lindquist, Nichols, Kober, \& Van Snellenberg, 2009; Yarkoni, Poldrack, Van Essen, \& Wager, 2010)). Collating more than 100 morphological differences reported in 21 studies that recruited more than 300 meditation practitioners, consistent changes were found in several regions of the brain (Fig. 1). For the sake of brevity, we discuss just a few of the most intriguing findings here. 
One region found to be altered in practitioners from a variety of contemplative backgrounds was the insula, a brain region key to interoceptive awareness of the body (e.g., awareness of respiration, heartbeat, abdominal sensations, and so on; (Craig, 2002, 2004, 2009; Critchley, Wiens, Rotshtein, Öhman, \& Dolan, 2004; Farb, Segal, \& Anderson, 2013)). Also consistently altered was the somatosensory cortex, the key region for exteroceptive awareness of the body (e.g., the sense of touch, pain, and so on; (Kaas, 1983; Penfield \& Boldrey, 1937)). Together, these changes in the insula and somatosensory cortex suggest that meditation practitioners have altered (perhaps heightened) awareness of their body, both inside and out - a hunch supported by evidence that meditators exhibit significantly more sensitive and objective reports of subtle bodily sensations (K.C.R. Fox et al., 2012; Sze, Gyurak, Yuan, \& Levenson, 2010), and further corroborated in a recent longitudinal study demonstrating enhanced heartbeat detection over time in practitioners learning mindfulness meditation (Bornemann \& Singer, 2017). Contemplative traditions often stress awareness of the body as a means of maintaining attention in the 'now' of the present moment, but as will be discussed in the next section, a heightened awareness of the body could also have important benefits when encountering emotional distress (Farb et al., 2010) and pain (Grant, Courtemanche, Duerden, Duncan, \& Rainville, 2010; Grant, Courtemanche, \& Rainville, 2011).

Another region consistently altered in practitioners from a variety of contemplative traditions is the rostrolateral prefrontal cortex (RLPFC), also known as frontopolar cortex. Although implicated in a wide variety of 'higher' cognitive tasks, such as probabilistic reasoning or integrating abstract information stored in working memory (Christoff \& Gabrieli, 2000; Ramnani \& Owen, 2004), perhaps most intriguing for our purposes is the 
apparent link between the RLPFC and introspective ability (Fleming, Ryu, Golfinos, \& Blackmon, 2014; Fleming, Weil, Nagy, Dolan, \& Rees, 2010). Given that most meditation practitioners spend significant time engaging in self-reflective, introspective practices, consistently altered structure in a brain region key to introspective ability suggests that such capacities might be enhanced with meditation training (K.C.R. Fox \& Christoff, 2014; A. Lutz \& Thompson, 2003) - a hypothesis supported by some preliminary research (Bornemann \& Singer, 2017; K.C.R. Fox et al., 2012; Jo, Hinterberger, Wittmann, \& Schmidt, 2015; Sze et al., 2010). As with body awareness, heightened introspective awareness might not only facilitate the goals of meditation practice itself, but might also have ancillary benefits. For instance, accurate introspection is thought to be crucial for facilitating insights into one's behavior in a manner that may play a key role in mitigating psychiatric disorders, such as relapse in major depression (Teasdale, 1999; Teasdale et al., 2002). Furthermore, long-term practitioners with heightened introspective awareness could help neuroscientists explore subtle cognitive phenomena that untrained participants are unable to notice or accurately report on (see next section).

Morphometric neuroimaging of long-term practitioners vs. short-term meditation training

The majority of the research discussed in the preceding section was based on comparing meditation-naïve control subjects to long-term practitioners with thousands of hours of meditation experience. As noted earlier (in our discussion of the brains of expert musicians), although such cross-sectional studies can reveal differences between groups, they cannot tell us if training induced these changes in the brain, or whether pre-existing differences in neuroanatomy might predispose certain people to persist in long-term 
training (in either music or meditation). Of course, both factors could also be at play, further complicating the situation. Longitudinal studies have helped to resolve this problem by examining the brains of people beginning to practice meditation both before and after a period of meditation training. By comparing any changes to a control group of subjects scanned at the same two time-points but undergoing no meditation training, we can make much better inferences as to whether meditation itself has caused the observed differences in brain structure. Several studies have employed this kind of pre-post longitudinal study to investigate meditation's effects on brain morphometry (Farb et al., 2013; Holzel et al., 2010; Holzel et al., 2011; Y.-Y. Tang, Lu, Fan, Yang, \& Posner, 2012; Y. Y. Tang et al., 2010). Intriguingly, the effects putatively induced by meditation training overlap considerably with those observed in long-term practitioners (Fig. 1), including consistent observations in regions related to emotional awareness and regulation (the anterior cingulate cortex), body awareness (the anterior insula), memory (hippocampus), and integration of information between the two cerebral hemispheres (corpus callosum) (K.C.R. Fox et al., 2014). Although these findings suggest that meditation training can indeed effect changes in brain structure, like other forms of skill learning (Draganski \& May, 2008), these results are based on only a handful of studies and need to be replicated and expanded in further work.

Methodological concerns for the morphometric neuroimaging of meditation

Despite all these apparent consistencies, the verdict is not yet in as to whether or not meditation is truly associated with altered brain structure, much less causes these alterations. Among many other methodological issues (K.C.R. Fox et al., 2014), one of the 
central concerns is publication bias or the 'file-drawer problem' - the tendency for researchers to publish only findings that show significant differences, and to refrain from publishing their findings when these show no differences between groups and abandon them in the proverbial file-drawer (Rosenthal, 1979). Under these conditions, which are rampant throughout academia (not just in meditation research), despite the fact that dozens of studies have now shown differences between meditation practitioners and controls (K.C.R. Fox et al., 2014), it could be that many studies have shown no differences, too - only no one has ever seen these 'null' results (besides the researchers who conducted the studies), because they have not been published. Statistical methods exist for estimating the degree of publication bias in a given field of study (Egger, Smith, Schneider, \& Minder, 1997), and without dwelling on the details, suffice to say that there is evidence for considerable publication bias in morphometric neuroimaging of meditation (K.C.R. Fox et al., 2014). For this reason (as well as others; (Thomas \& Baker, 2013)), findings from morphometric neuroimaging of meditation need to be interpreted with caution.

Figure 1. Consistent findings from morphometric neuroimaging of meditation practitioners.
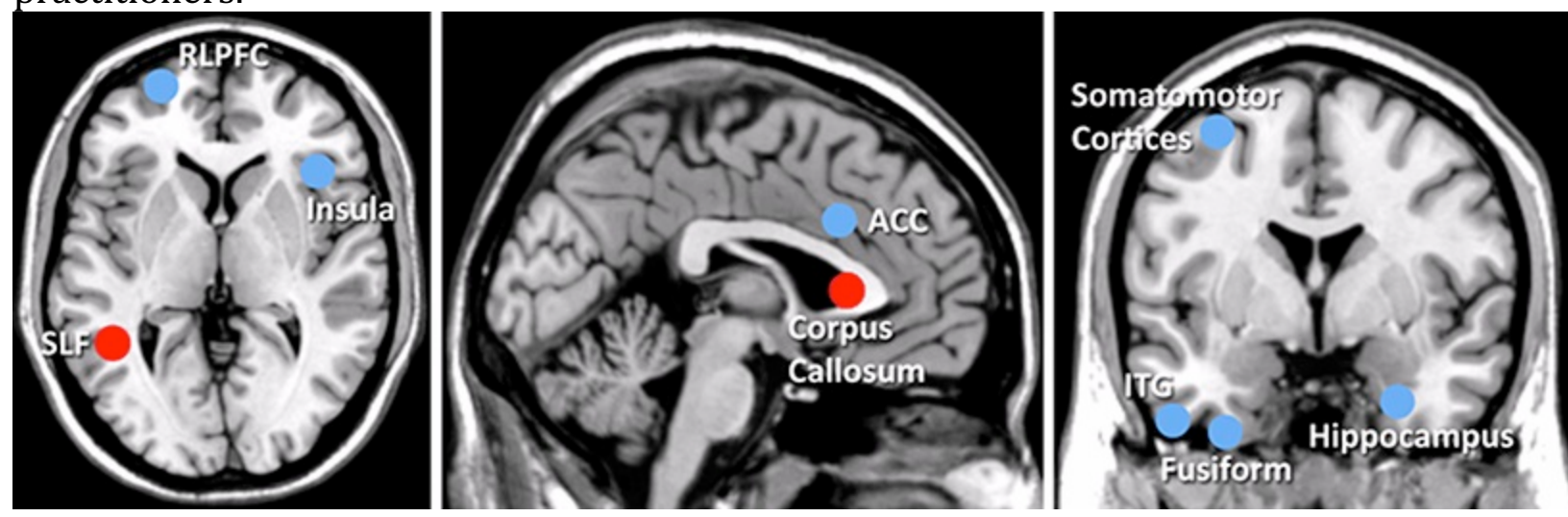

Putative consistent changes in the brain structure associated with the practice of meditation. Grey matter differences are indicated by blue circles, differences in white matter by red circles. ACC: anterior cingulate cortex; ITG: inferior temporal gyrus; RLPFC: rostrolateral prefrontal cortex; SLF: superior longitudinal fasciculus. Reproduced, with permission, from Fox et al. (2014). 


\section{Functional neuroimaging of meditation}

Starting in 1999, neuroscientists began to apply methods of functional neuroimaging to the investigation of meditation (Lou et al., 1999). In contrast to the morphometric neuroimaging techniques discussed in the previous section, which interrogate various aspects of brain structure, functional neuroimaging methods measure the brain at work. Functional magnetic resonance imaging (fMRI) and positron emission tomography (PET) are typically used to measure various aspects of changes of blood flow in the brain (a highly useful correlate of the averaged activity of the brain's neurons, despite being many steps removed from actual neuroelectric activity (Logothetis, Pauls, Augath, Trinath, \& Oeltermann, 2001; Mukamel et al., 2005)). Examining changes in blood flow throughout the brain can provide a proxy measure of how different brain regions are recruited during essentially any cognitive task a person can engage in while lying down in a brain scanner including meditation.

There are at least three ways in which meditation can be investigated with functional neuroimaging. The first and most basic is to simply examine the neural correlates of engaging in a particular form of meditation (for instance, have practitioners engage in a breath awareness meditation and look at brain activity compared to some baseline). Many studies have taken such an approach in an effort to better understand the fundamental neural basis of various meditation techniques (K.C.R. Fox, Dixon, et al., 2016). A second approach is to employ long-term practitioners, or novices after brief meditation training, and explore whether meditation alters the brain's response to a variety of tasks and experiences (for instance, having untrained people vs. trained meditation practitioners view distressing videos (Farb et al., 2010)). A third and more experimental method is to 
harness the putatively enhanced introspective abilities of long-term meditation practitioners (K.C.R. Fox et al., 2012; Sze et al., 2010) to investigate subtle and difficult-tostudy cognitive phenomena (Berman \& Stevens, 2015; Ellamil et al., 2016). Examples of each type of approach are discussed in the following subsections.

\section{Neural correlates of meditation practices}

Meditation comprises hundreds of different techniques, but many of these can be grouped into a few broad categories. One scheme uses three basic categories: focused attention, open monitoring, and loving-kindness/compassion (K.C.R. Fox, Dixon, et al., 2016; Antoine Lutz, Jha, Dunne, \& Saron, 2015; A. Lutz et al., 2008). Focused attention meditation involves focalizing and sustaining attention on a single object, often the sensations of respiration or a visual point of fixation. A related practice, sometimes grouped with focused attention but which we consider separately for the purposes of this chapter, is mantra meditation, a focused attention practice wherein the single focus of attention is a phrase repeated by the practitioner (we treat mantra meditation as a distinct category because of its distinctive motor/verbalization component). Open monitoring (sometimes referred to as 'open awareness') is a broad category encompassing many forms of meditation that involve a non-judgmental, non-attached, broad attention to everything arising in one's experience, be it visions, sounds, somatic sensations, and one's own thoughts. Finally, loving-kindness and compassion forms of meditation involve cultivating specific positive emotional and relational states of mind characterized by love and the intention to relieve suffering in self and/or others. 
Each of these four categories of meditation has been explored with functional neuroimaging in some detail over the past two decades. The most salient finding from this considerable body of work is that psychologically distinct meditation practices show correspondingly diverse neural correlates. For instance, focused attention meditation has been shown to recruit several regions of the brain canonically involved in top-down control of attention and other executive processes, including the right dorsolateral prefrontal cortex, the dorsal anterior cingulate cortex, and the premotor cortex (Fig. 2). In contrast, mantra meditation (a subtype of focused attention practice), in which practitioners repeatedly recite a specific phrase or word (either out loud or, more often, subvocally), involves a notable recruitment of motor regions, including the supplementary motor area and Broca's area, which is key to speech production (Fig. 2). Similar to focused attention, open monitoring meditation yielded marked recruitment of prefrontal brain areas involved in the top-down control of attention, but also displayed recruitment of the insula (a region involved in awareness of inner body states) on both sides of the brain - a finding suggesting that this form of meditation focuses attention on the present-moment experiences of the body (Farb et al., 2007). Finally, loving-kindness and compassion forms of meditation yielded a variety of brain activations consistent with other neuroimaging studies of normal people generating or expressing emotions like compassion and empathy (Fig. 2).

Other types of meditation that do not fit easily within these four categories have only rarely been investigated with functional neuroimaging, but the results of some preliminary investigations are nonetheless intriguing (Josipovic, Dinstein, Weber, \& Heeger, 2011; Kakigi et al., 2005; Kjaer et al., 2002; Lou et al., 1999). For instance, an early 
study of the neural correlates of visualization meditation (where practitioners imagine visual scenes and figures in vivid detail) found widespread activation of visual brain regions (Lou et al., 1999) - a finding not observed during any other form of meditation (K.C.R. Fox, Dixon, et al., 2016). A recent study of non-dual awareness practice - which can be conceived as an advanced open-awareness practice wherein the experience of an observer relating to observed phenomena of experience dissolves into an all-encompassing unity of experience - found decreases in the normally anti-correlated activations of the major circuits of the brain such as the default mode network and the central executive network (Josipovic, 2014; Josipovic et al., 2011).

Differences aside, some similarities are also telling. As noted above, one of the most reliable findings from morphometric neuroimaging of meditation practitioners is structural alteration of the insula (K.C.R. Fox et al., 2014), a brain region key to interoceptive awareness of the body (Craig, 2002, 2004, 2009; Critchley et al., 2004; Farb et al., 2013). Consistent with this finding, Fox et al. (2016) found that all four broad categories of meditation consistently modulated activity in the insula (Fig. 2). Although these effects included a mix of activations (for focused attention, open monitoring, and compassion meditations) and deactivations (mantra recitation), suggesting that not every form of meditation modulates the insula in the same way, the results nonetheless point to this region's importance across an array of contemplative practices (Fig. 2). Given the insula's role in interoceptive awareness, and considering that awareness and regulation of breathing and other aspects of the body are central to most forms of meditation, consistent structural (K.C.R. Fox et al., 2014) and functional (K.C.R. Fox, Dixon, et al., 2016) alterations in the insula are not especially surprising. The unique finding of deactivation of the insula 
during mantra meditation might be related to this practice's focus on generating

verbalizations, and regulating respiration accordingly, in a top-down manner, rather than paying attention to the natural fluctuations of breathing in a bottom-up way, as in most other forms of contemplative practice. It may also point to a decreased tendency of mantra practice to enhance bodily awareness relative to focused attention on bodily processes, open monitoring, and loving-kindness/compassion practices.

Figure 2. Meta-analytic activations and deactivations for four categories of meditation.

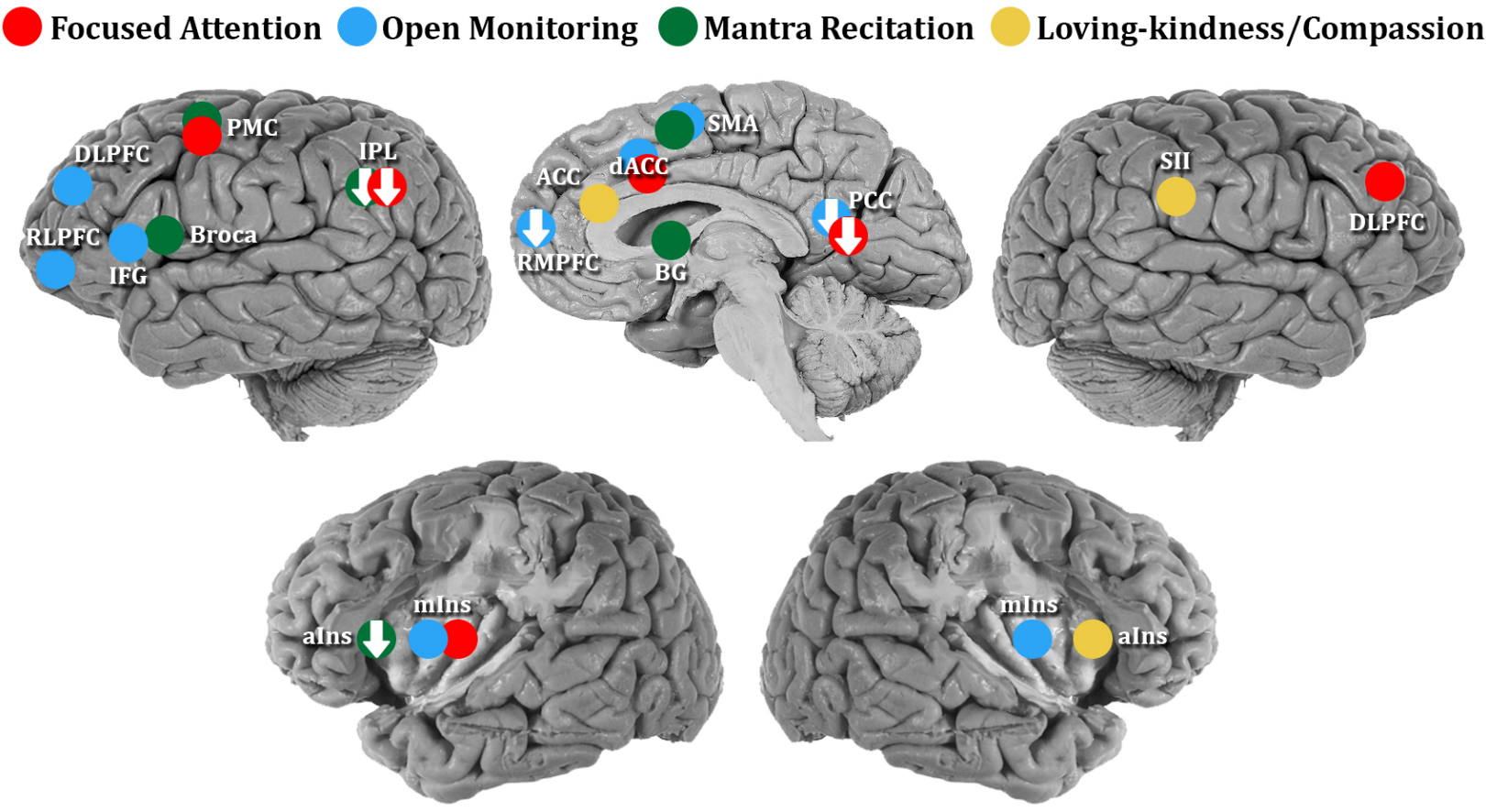

Activations are represented by filled circles, deactivations by circles containing downward arrows. Regional labels are approximate, and are shown for illustrative purposes only. For details, see tables of results, main figures, and supplementary figures in Fox et al. (2016). ACC: anterior cingulate cortex; alns: anterior insula; BG: basal ganglia; Broca: Broca's area; dACC: dorsal anterior cingulate cortex; DLPFC: dorsolateral prefrontal cortex; IFG: inferior frontal gyrus; IPL: inferior parietal lobule; mIns: mid-insula; PCC: posterior cingulate cortex; PMC: premotor cortex; RLPFC: rostrolateral prefrontal cortex; RMPFC: rostromedial prefrontal cortex; SII: secondary somatosensory cortices; SMA: supplementary motor area. Reproduced, with permission, from Fox et al. (2016). 
How meditation changes the brain's response to tasks and experiences

Another approach is to examine not just the neural correlates of meditation in and of itself, but how meditation practice alters the brain's responses to specific tasks and emotional experiences. For instance, viewing distressing (sadness- or fear-provoking) images and videos is known to have widespread effects on brain activity. Farb and colleagues (2010) investigated whether engaging in an 8-week mindfulness meditation course would alter these patterns of brain activity when viewing sadness-provoking videos. In control subjects that had not undergone any meditation training, they found that watching sad (compared to neutral) videos elicited recruitment in multiple midline default network regions associated with self-referential processing, memory retrieval, mindwandering, and rumination (Christoff, Irving, Fox, Spreng, \& Andrews-Hanna, 2016; K.C.R. Fox et al., 2018; K. C. R. Fox, Foster, Kucyi, Daitch, \& Parvizi, 2018; K.C.R. Fox, Spreng, Ellamil, Andrews-Hanna, \& Christoff, 2015; Northoff et al., 2006). In contrast, those who had undergone mindfulness training showed increased activation in the insula (as noted above, a region key to interoception) and executive brain regions in the lateral prefrontal cortex. Both groups reported that the videos elicited comparable levels of sadness, however in the mindfulness group an increased recruitment of body awareness-related brain regions, rather than default network regions involved in mind-wandering and conceptual thinking, suggested that the response was perhaps more present-centered and detached from narrative processing in those who had undergone mindfulness training (Farb et al., 2010).

Functional neuroimaging has also shown that meditation can alter the neural correlates of the experience of pain in a similar fashion. Beyond the purely sensory aspects 
of pain, the experience of pain ('nociception') tends to also involve thoughts that relate the pain to the self, as well as distress and various other negative emotional valuations of the sensory experience (Grant, 2014; Grant et al., 2011; Rainville, Duncan, Price, Carrier, \& Bushnell, 1997). These cognitive-affective elaborations appear to be dissociable from, and temporally subsequent to, the purely sensory aspects of pain - and what's more, they may contribute significantly to the subjectively experienced unpleasantness of nociceptive experience (Rainville et al., 1997). A recent study using fMRI explored whether mindfulness meditation might reduce the habitual affective-elaborative component of pain, by exploring differences in brain activity between long-term Zen practitioners and meditation-naïve controls (Grant et al., 2011). Earlier studies demonstrated that the same group of Zen practitioners exhibited higher self-reported pain thresholds (Grant \& Rainville, 2009) and increased cortical thickness in sensory pain areas (Grant et al., 2010). Elaborating on these behavioral findings for pain thresholds, the researchers found that pain elicited greater brain activations in sensory pain areas in the meditators, including the thalamus, insula, and dorsal anterior cingulate cortex - suggesting that the meditators elaborated less on their pain, and instead focused more on its immediate sensory components (Grant et al., 2011). Further support for this interpretation came from the finding that functional connectivity between primary sensory pain areas, and secondary affective-elaborative areas, was increased in controls and decreased in the long-term Zen practitioners (Grant et al., 2011), again supporting the idea that novices dwelled on their pain with emotional and cognitive associations, whereas the meditators tended to remain focused on its more purely sensory aspects. Intriguingly, the degree of this decoupling in meditation practitioners significantly predicted their lower pain sensitivity - offering 
perhaps the most persuasive evidence for the aforementioned interpretation. Further work by others has reinforced this general understanding of the effects of mindfulness on the brain processing of pain, revealing that short-term training in mindfulness results in similar changes in the neural underpinnings of pain processing (Zeidan et al., 2016; Zeidan et al., 2015; Zeidan, Grant, Brown, McHaffie, \& Coghill, 2012; Zeidan et al., 2011).

Harnessing meditation to explore subtle neurocognitive phenomena

Researchers have long suggested that the putatively enhanced attentional (MacLean et al., 2010) and introspective (K.C.R. Fox et al., 2012) abilities of long-term meditation practitioners might be harnessed to help neuroscientists explore subtle cognitive phenomena not easily investigated with untrained participants - an approach falling within the purview of the field of neurophenomenology (Fazelpour \& Thompson, 2015; A. Lutz \& Thompson, 2003; Varela, 1996). For instance, very little is understood from a neuroscientific perspective about how new thoughts spontaneously arise in our minds (Christoff, 2012; Christoff, Ream, \& Gabrieli, 2004), yet this phenomenon is key to an understanding of creative thinking, scientific discovery, and even some forms of mental illness, such as depression (Christoff, Gordon, \& Smith, 2011; Christoff et al., 2016; K.C.R. Fox, Andrews-Hanna, \& Christoff, 2016; K.C.R. Fox \& Christoff, 2018). A general picture of brain regions involved in these forms of internally-oriented thinking is emerging (K.C.R. Fox et al., 2015), but the functional role of each region, and which areas are involved specifically in generating thoughts, remains unknown. At the same time, certain meditation traditions, for instance vipassana or 'insight' practices, focus very specifically and 
intensively on detecting and observing the arising of thoughts (Goenka, 2000). In a recent study, Ellamil and colleagues (2016) therefore recruited highly-experienced vipassana practitioners (with an average of 8339 hrs of practice) to meditate in an MRI scanner and indicate with a button-press the exact moment they noticed thought(s) arising. Working backwards from this button-press, the investigators examined which brain areas were most active just prior to conscious awareness of a thought arising. They found that the medial temporal lobe and certain regions belonging to the default network were most active as a thought was arising, whereas other regions thought to be involved in spontaneous forms of thought showed peak activity several seconds later, suggesting that they are involved in the elaboration or evaluation of these thoughts (rather than their generation) (Ellamil et al., 2016). This study provides a good example of how the specific expertise of highly-experienced meditation practitioners was able to help shed light on the brain dynamics of a subtle yet important cognitive process that may have been difficult to investigate in any other way. Further work could shed light on the neural basis of more unusual experiences in long-term meditators, for instance prolonged states of narrativefree awareness. 


\section{The electrophysiology of meditation}

Electroencephalography (EEG) involves the application of electrodes to the scalp in order to measure the electrical fields produced by the brain. EEG can detect very fast fluctuations in brain activity (on the millisecond scale), but because the signal is filtered through the skull and skin, spatial resolution tends to be poor. EEG is therefore an excellent tool for determining when changes in brain activity take place, but tells us much less about where in the brain they are happening. Functional MRI generally has the opposite profile poor temporal but good spatial resolution - making the two methods good complements to one another.

Crucial to understanding EEG studies is an appreciation that the human brain establishes natural rhythms that synchronize electrical activity from its 100 billion neurons (Buzsaki, 2006). These synchronized oscillations can be detected as 'brainwaves' with characteristic frequencies (i.e., cycles per second, measured in Hertz, or Hz), and different frequencies, when dominant, broadly correspond to different states of consciousness and alertness (Fig. 3). For instance, the slowest brainwaves (0.5-4 Hz) are known as 'delta' waves and are characteristic of deep sleep and, in most people, a lack of conscious awareness (Fig. 3). In contrast, normal wakeful alertness tends to be associated with a mix of alpha, beta $(13-32 \mathrm{~Hz})$, and gamma $(\gtrsim 30 \mathrm{~Hz})$ waves, whereas restful waking with eyes closed results in enhanced brainwaves in the alpha range and is associated with feelings of relaxation $(8-13 \mathrm{~Hz})$.

This basic rubric is well-validated and agreed upon, if grossly simplified. In reality, the brain is generating a mix of frequencies across the delta, theta, alpha, beta, and gamma ranges in every given state of awareness, and the relative strength of each frequency in 
each brain area is constantly changing. Overall, our understanding of how brain rhythms are affected by experience and mental training remains relatively poor, although some progress with regards to meditation and the EEG has been made. EEG studies of meditation have been conducted for over 50 years (Cahn \& Polich, 2006), with two general approaches: (i) investigation of meditation states, i.e., the brain's electrical activity during a given meditation practice; or (ii) investigation of meditation traits, i.e., persisting differences in the electrical activity of the brains of long-term meditation practitioners compared to meditation-naïve control subjects. Because research results are complex and far from wholly consistent, in the following sections we first present an overview of what has been found and then subsequently attempt to integrate and interpret the many disparate findings. 
Figure 3. The standard human brain rhythm frequencies.

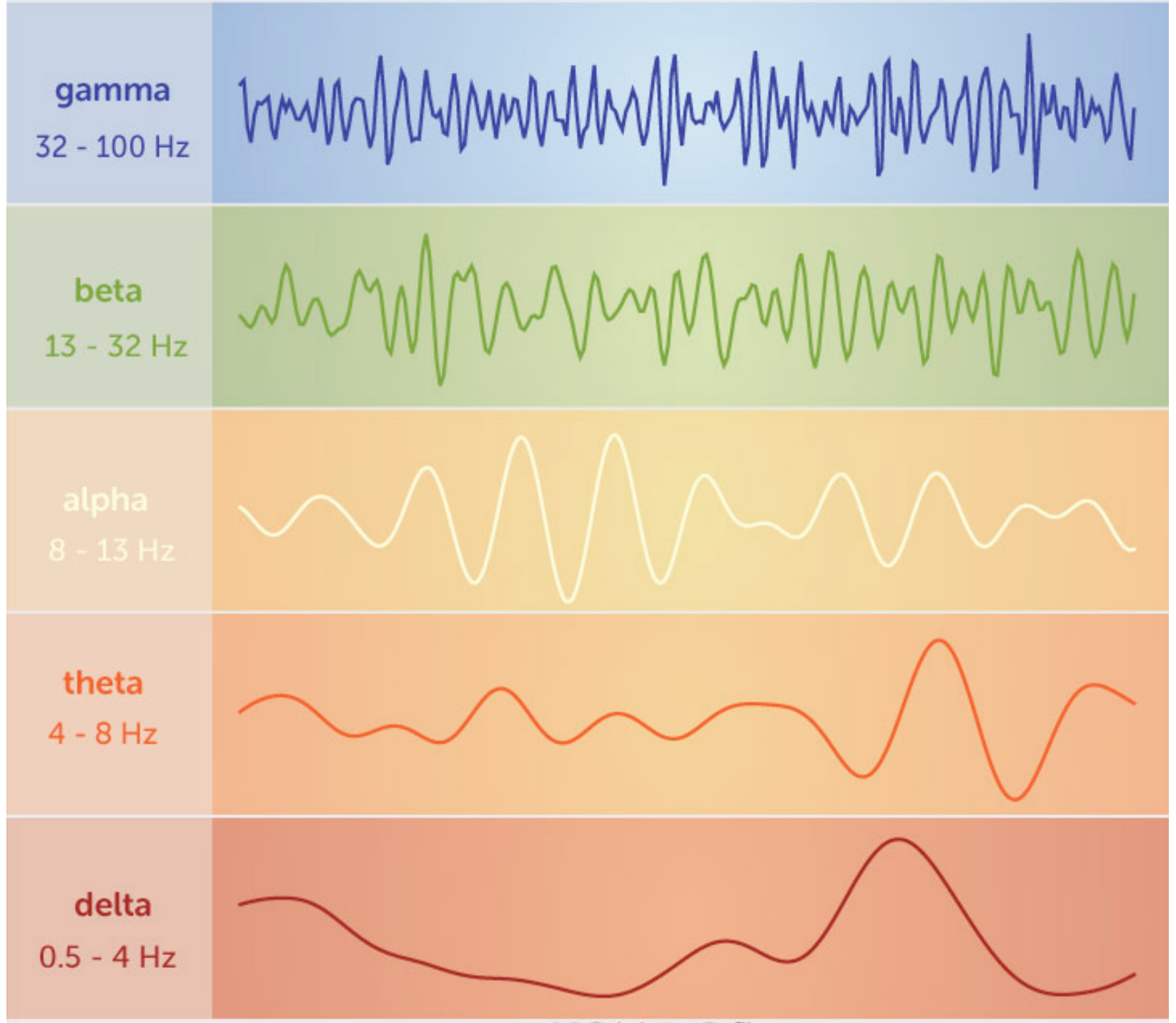

General electrophysiological correlates of meditation

Although the neuroelectric correlates of meditative states and traits of consciousness are not yet firmly established, the primary findings have implicated increases in theta (4-7 $\mathrm{Hz}$ ) and alpha band (8-12 Hz) power (Andresen, 2000; Cahn \& Polich, 2006; Davidson, 1976; Fenwick, 1987; Schuman, 1980; Shapiro \& Walsh, 1984; West, 1980). The large number of studies showing enhanced theta and/or alpha power in both novices and 
experts suggests that enhancements of these electrocortical rhythms are somehow meaningfully related to meditative practices.

A number of the more recent studies showing specific state-related changes during meditation in more advanced practitioners have found alterations in faster beta $(\sim 12-30$ $\mathrm{Hz})$ and gamma $(>30 \mathrm{~Hz})$ frequency ranges. These findings suggest that as meditative expertise develops there may be trait-like alterations in theta and alpha early on, and laterdeveloping alterations in faster beta and gamma frequencies in association with experiencing more and more refined states of meditative awareness.

For instance, numerous recent studies of meditation have demonstrated effects on beta activity (Dor-Ziderman, Berkovich-Ohana, Glicksohn, \& Goldstein, 2013; Faber et al., 2015; Hauswald, Übelacker, Leske, \& Weisz, 2015; Saggar et al., 2012; Tanaka et al., 2015). Specific examples of such findings include an assessment of experienced Zen meditators demonstrating a state-related decrease in posterior beta power in combination with increased right frontotemporal alpha power (Faber et al., 2015). Another study of Zen meditators similarly found a decrease in beta power in combination with a decrease in delta power (Hauswald et al., 2015). Perhaps the most reliable finding to date was demonstrated in a well-controlled longitudinal study with a cohort of practitioners randomized to an intensive 3-month retreat, including assessments before vs. after in both the meditation practitioners and control participants (Saggar et al., 2012). This study found only one major effect on band power across any of the assessed frequencies from delta to gamma - decreases in centroparietal beta power (Saggar et al., 2012). In this context it is important to note that one major interpretation of decreases in beta power is that both alpha and beta EEG power have been found to be inversely related to cortical excitability 
and target detection accuracy; conversely, then, decreases in beta power may be related to enhanced cortical excitability and sensory acuity.

Recent studies of meditation have focused also on the gamma band $(30-80 \mathrm{~Hz})$, which is known to be associated with the current contents of awareness and perceptual binding (Fries, 2009; Scheeringa et al., 2011). Because the gamma range is subject to potential large-amplitude muscle- and eye-movement related artifacts, it is difficult to measure with absolute confidence, although methods have been developed to address this issue and are actively being assessed for reliability in dissociating cortical gamma activity from scalp and extraocular muscle gamma activity. The first modern quantitative study demonstrating specific gamma frequency effects in meditation assessed highly experienced Tibetan Buddhist meditators vs. novices while engaged in three separate techniques: one-pointed concentration on an object, open attention without an object, and a state of non-referential love and compassion (A. Lutz, Greischar, Ricard, Converse, \& Davidson, 2003). Large increases in $\sim 40 \mathrm{~Hz}$ gamma power were observed in the meditators as both a state effect of meditation and a trait elevation relative to non-meditator controls. A number of further studies over the past ten years have found gamma power increases associated with meditative practice during waking meditation practice (Berkovich-Ohana, Glicksohn, \& Goldstein, 2012; Braboszcz, Cahn, Levy, Fernandez, \& Delorme, 2017; Cahn, Delorme, \& Polich, 2010; Dentico et al., 2016; Ferrarelli et al., 2013).

\section{Understanding and interpreting electrophysiological findings in meditation research}

Detecting and measuring the electrophysiological effects of meditation is one thing; understanding the functional significance of such differences is another. There are two 
basic approaches to an understanding and interpretation of electrophysiological findings in meditation research. The first, detailed in this section, is to relate observed changes to the broader field of EEG research. An understanding of what various EEG rhythms are generally thought to represent can shed light on what functional role such changes might have in the specific context of meditation. A second approach, explored in the next section, is to collect detailed first-person reports from meditation practitioners and explore the electrophysiological correlates of particular subjective states.

Recent basic neurophysiological investigations of the functional significance of cortical rhythms in the theta, alpha, beta, and gamma frequency ranges indicate that both alpha and beta are important in top-down attentional control, i.e., voluntarily orienting attention toward an object of one's own choosing; gamma, instead, appears to be more significantly related to bottom-up stimulus processing, i.e., allowing sensory stimuli to capture attention and then binding them together into unified perceptual experiences (Richter, Thompson, Bosman, \& Fries, 2017). But because of the difficulties in localizing the specific spatial source of EEG signals, aligning specific EEG findings with the spatially-specific findings from fMRI (discussed above) remains challenging. Attaining better spatial resolution with EEG might someday provide a much more thorough understanding of the meaning of electrocortical findings.

Nonetheless, in relating investigations of the general functional significance of EEG band power to specific findings from electrophysiological studies of meditation, some meaningful trends emerge. For instance, enhanced frontal theta power is often correlated with decreased default network activation in simultaneous EEG/fMRI studies (Meltzer, Negishi, Mayes, \& Constable, 2007; Murta, Leite, Carmichael, Figueiredo, \& Lemieux, 2015; 
Scheeringa et al., 2008). The enhancement of frontal theta often observed in relation to meditative practice could therefore be related to the meditative capacity to decrease default network activation, as has been observed in fMRI studies (cf. Fig. 2). Because default network activation has been consistently linked to mind-wandering and other forms of internally-directed and self-referential thought (Christoff, Gordon, Smallwood, Smith, \& Schooler, 2009; Christoff et al., 2016; Dixon, Fox, \& Christoff, 2014; Ellamil et al., 2016; K.C.R. Fox et al., 2015), default network deactivation might be related to the fact that meditation training is associated with a lower frequency of mind-wandering (Brandmeyer \& Delorme, 2016; Mrazek, Franklin, Phillips, Baird, \& Schooler, 2013; Rahl, Lindsay, Pacilio, Brown, \& Creswell, 2017; Zanesco et al., 2016). Overall, then, research suggests that meditation may be associated with decreased quantity of mind-wandering in conjunction with increased periods of higher theta-alpha power during periods of greater meditative quietude.

With respect to enhanced alpha power, the functional significance of $8-12 \mathrm{~Hz}$ alpha activity in the human cortex is still far from clear, although some recent insights are instructive. For instance, increased alpha power is observed in sensory areas responsible for processing that is being purposefully ignored, and decreased alpha power in areas responsible for sensory processing that is being attended to. This implies that at least one functional role for increased alpha power observed is enhanced inhibition of elaborative processing in the cortex from which alpha emanates; i.e., increased alpha power over a given part of the brain might be a marker that this region is functionally inhibited and thus less actively processing information. It therefore seems reasonable to interpret the frequent finding of enhancements of frontal theta as a proxy for enhanced attentional 
absorption in a non-conceptual domain and resultant decrease in default network activation, and the enhanced alpha power related to functional inhibition of specific brain circuitry depending on where the alpha enhancements are seen.

With respect to beta activity, the canonical understanding has been that beta activity is related to active processing, but there is now growing evidence that, as with alpha, beta activity too is related to decreased metabolic demand and may serve an inhibitory processing function (Murta et al., 2015; Scheeringa et al., 2011; Scheeringa, Koopmans, van Mourik, Jensen, \& Norris, 2016), and at least in the somatosensory domain serves as a topdown mediator of decreased cortical excitability, much like alpha (van Ede, de Lange, Jensen, \& Maris, 2011). The relative decreases in beta power that a number of recent studies have demonstrated may therefore be related to enhancements in cortical excitability and sensory acuity.

Neurophenomenological approaches to the electrophysiology of meditation

Beyond speculations based on the general significance of various EEG rhythms, a more targeted approach can be taken by gathering detailed first-person reports from meditation practitioners and exploring how these subjective states are related to specific electrophysiological markers. Such an approach often falls under the umbrella of the method of neurophenomenology, as discussed earlier (Fazelpour \& Thompson, 2015; A. Lutz \& Thompson, 2003; Varela, 1996). Early efforts to apply neurophenomenological techniques to meditative states were undertaken by researchers of Transcendental Meditation. In these early studies, periods of breath suspension, as well as increased alpha power and alpha inter-channel coherence, were found to characterize periods of self- 
described 'inner silence' (Badawi, Wallace, Orme-Johnson, \& Rouzere, 1984; Farrow \& Hebert, 1982; Travis, 2001; Travis \& Pearson, 2000). More recent investigations with expert meditators in other traditions have attempted to probe specific refined states of meditative awareness using a neurophenomenological approach. These include investigation of the jhānas (a sequence of meditative absorptions described in traditional Buddhist teachings) (DeLosAngeles et al., 2016; Hagerty et al., 2013); non-dual states of awareness (Berman \& Stevens, 2015; Schoenberg, Ruf, Churchill, Brown, \& Brewer, 2018); thoughtless emptiness (Hinterberger, Schmidt, Kamei, \& Walach, 2014); and the experiential dimensions of selflessness, timelessness, and spacelessness (Berkovich-Ohana, Dor-Ziderman, Glicksohn, \& Goldstein, 2013; Dor-Ziderman, Ataria, Fulder, Goldstein, \& Berkovich-Ohana, 2016; Dor-Ziderman et al., 2013).

For instance, exploration of jhānic absorptions yielded findings of increased theta, alpha, and gamma power in one case-report (Hagerty et al., 2013), and increased frontal theta and alpha power combined with decreased central beta and gamma power in a study of 12 long-term meditators (DeLosAngeles et al., 2016). In contrast to such focused absorption states, guided non-dual awareness meditation states have been found to be characterized by large broadband decreases in alpha, beta, and gamma power, with subsequent increases in beta and gamma power in successively more refined states of awareness (Schoenberg et al., 2018). In another study, wherein experienced practitioners were instructed to cultivate a state of 'thoughtless emptiness,' this experience was found to be correlated with reduced delta, theta, and beta power relative to the resting state; in contrast, focused attention and mindful presence states were associated with greater gamma power relative to thoughtless emptiness states (Hinterberger et al., 2014). A recent 
study using magnetoencephalography (MEG), a method that, like EEG, also measures the brain's electromagnetic potentials, investigated states of 'selflessness' in long-term meditators. When the practitioners indicated that they were transitioning from a narrative style of self-awareness to a more minimal self-awareness, the researchers observed a decrease in frontal gamma power; the further transition from a minimal self-awareness to total 'selflessness' was accompanied by a decrease in centroparietal beta power (DorZiderman et al., 2016; Dor-Ziderman et al., 2013). In contrast, the transition to an experience of timelessness and spacelessness in the same group of subjects was associated with an increase in frontal theta power (Berkovich-Ohana et al., 2013).

A second type of neurophenomenological approach has been to probe participants or ask them to self-report regarding specific epochs of experience during their meditation sessions while undergoing electrophysiological recording. One such study assessed selfreported 'non-thought' or 'non-dual' states and found that greater delta, theta, and alpha power, in combination with lower beta and gamma power, were observed when comparing such short periods with the average activity over the long meditation session (Berman \& Stevens, 2015). In another study of long-term practitioners, intermittent probes during the meditation session asked the meditators about their meditative depth and incidence of mind-wandering; increased theta and alpha power were demonstrated in epochs of greater self-reported meditative absorption relative to periods higher self-reported mindwandering (Brandmeyer \& Delorme, 2016). 


\section{Summary}

In sum, while electrophysiological studies of meditation have been extensive, many questions remain. The most frequently demonstrated findings include enhanced theta and alpha power as both state and trait effects of meditation, but more recent studies point toward beta and gamma effects, especially in longer-term practitioners. The application of neurophenomenological methods to meditative states alongside EEG recordings has begun in earnest over the past five years, but findings are as yet somewhat inconsistent. One apparent trend from this work, however, is that more concentrative states of meditation tend to demonstrate increases in theta-alpha power, whereas open-awareness types of meditative states appear to demonstrate some consistent decreases in power for both slower and faster frequencies.

Unlike fMRI signals, EEG signals are temporally specific and spatially diffuse; part of the explanation for the great variety of findings reported to date may therefore be the lack of consensus on methods of localizing observed effects. Another source of confusion could be the potentially diverse state-trait changes associated with the many different set points that individuals start at before engaging in meditation (cf. (Mascaro, Rilling, Negi, \& Raison, 2013) and extensive discussion in (K.C.R. Fox, Dixon, et al., 2016)). Further advances in signal processing will likely help resolve some of the outstanding questions regarding which frequency bands are related to specific meditative states and traits. 


\section{Meditation and brain health}

Recent years have seen increasing efforts to understand how the long- and shortterm practice of meditation relates to brain health. Although investigation of the relationship between meditation and brain health in neurodegenerative and psychiatric disease remains in its infancy, given the increasing popularity of meditation interventions in clinical settings we expect a rapid proliferation of such investigations in the near future. Here we discuss just two avenues of inquiry that have already shown promise. One line of research has investigated how meditation might mitigate age-related cognitive decline, and potentially, more serious conditions such as dementia and Alzheimer's disease, which are associated with progressive atrophy of brain tissue. Another line of research has also examined how meditation might alter brain activity in specific psychiatric conditions like depression, attention-deficit hyperactivity disorder (ADHD), social anxiety disorder, and bipolar disorder.

\section{Meditation and age-related brain atrophy and cognitive decline}

Both the structure and functioning of the brain are negatively impacted by normal aging, which progressively reduces the amount and density of grey matter, as well as reducing the metabolic rate of the brain (Chételat et al., 2013; Fjell \& Walhovd, 2010), and these structural and functional changes are associated with cognitive impairments such as memory loss, poor attentional focus, and impaired executive function (i.e., voluntary control and flexible shifting of attention) (N. Fox, Scahill, Crum, \& Rossor, 1999; Rusinek et al., 2003). There is evidence that various lifestyle interventions (such as exercise) might help mitigate these cognitive problems (Christie et al., 2017; Norton, Matthews, Barnes, 
Yaffe, \& Brayne, 2014). Preliminary findings suggest that long-term meditation practice, too, might be beneficial (Gard, Hölzel, \& Lazar, 2014), raising the question of whether these putative benefits might be mediated by corresponding differences in brain structure and function.

Although firm conclusions are unwarranted at this early stage, several pilot studies have addressed this question in recent years. For instance, Pagnoni \& Cekic (2007) investigated brain grey matter volume in 13 long-term Zen meditation practitioners and 13 age- and sex-matched controls between the ages of 25 and 50 . They found that whereas the control subjects exhibited a sizable negative correlation $(r=-.56)$ between age and total grey matter volume (as expected based on trends in the general population), the meditation practitioners showed no such relationship $(r=.006)$. That is, the brains of 50 year-old Zen practitioners showed no overall grey matter differences from those of their much younger counterparts, whereas among control subjects, age significantly predicted less grey matter volume. Intriguingly, a similar trend was observed for a demanding sustained attention task administered to all participants: whereas older control subjects made considerably more errors on the task, performance remained high among nearly all Zen practitioners, and showed no significant relationship with age (Pagnoni \& Cekic, 2007). A related study by Lazar and colleagues (2005) similarly found that grey matter density in the rostrolateral prefrontal cortex, an area of the brain linked to higher cognitive abilities like introspection (Fleming \& Dolan, 2012), differed significantly between long-term practitioners and controls. Whereas control subjects showed the anticipated negative correlation between grey matter density and age in this region $(r=-.76)$, the meditation practitioners again showed no decline in grey matter with age $(r=.05)$ (Lazar et al., 2005). 
A handful of more recent studies have reported broadly congruent findings, providing some further support for these claims (Chételat et al., 2017; Kurth, Cherbuin, \& Luders, 2015; Luders, Cherbuin, \& Gaser, 2016; Luders, Cherbuin, Kurth, \& Lauche, 2015; Wells et al., 2013). So far, none of these studies has established a causal link between meditation practice and these brain structural differences over the lifespan: for instance, people who naturally experience less cognitive decline and brain aging might also be more motivated, and better able, to consistently engage in a meditation practice, or non-specific effects of a meditation practice, such as reduced stress or a more vegetarian diet, could explain the observed correlations. Nonetheless, these intriguing relationships should be pursued further in future research.

We are aware of two studies that have further investigated meditation and aging with functional, rather than morphometric, neuroimaging (Chételat et al., 2017; Wells et al., 2013). Wells and colleagues (2013) investigated the neural effects of mindfulness meditation on adults with mild cognitive impairment (MCI), often a precursor to dementia and Alzheimer's disease. Although the researchers did not measure whether mindfulness meditation actually affected the symptoms of MCI, they did find changes in neural markers that suggest it might be beneficial. These promising indicators included less atrophy in the hippocampus (known to degenerate in dementia and Alzheimer's patients (Buckner et al., 2005; Kaye et al., 1997)) as well as increased functional connectivity (i.e., correlated activity) between various brain regions critical to memory and especially susceptible to degeneration with aging (Wells et al., 2013).

Like age-related grey matter atrophy (Fjell \& Walhovd, 2010), glucose metabolism tends to decrease with aging throughout the brain (Chételat et al., 2013). Chételat and 
colleagues (2017) recently used PET to examine whether glucose metabolism (a proxy for how active a brain area is) differed in elderly meditation practitioners (average age $=65$ years, minimum of 10,000 hours of meditation experience) compared to control subjects without meditation experience. Reminiscent of the results from brain structure and aging in meditation practitioners, they found that glucose metabolism was significantly increased in several brain regions in the elderly meditation practitioners, again suggesting some protective effects against normal aging processes. Again, however, other differences in people who tend to consistently practice meditation, such as lower stress or particular diets, are generally not measured or accounted for, and could conceivably play a large role in the observed differences.

\section{Meditation and the neural basis of addiction and mental illness}

Beyond cognitive decline and brain atrophy associated with aging, a handful of studies have investigated the neural basis of how meditation might ameliorate the symptoms of psychiatric conditions like depression (Bostanov, Keune, Kotchoubey, \& Hautzinger, 2012; Chen et al., 2015; Schoenberg \& Speckens, 2015), ADHD (Schoenberg et al., 2014), social anxiety disorder (Goldin \& Gross, 2010; Goldin, Ziv, Jazaieri, \& Gross, 2012; Goldin, Ziv, Jazaieri, Hahn, \& Gross, 2013), and bipolar disorder (Ives-Deliperi, Howells, Stein, Meintjes, \& Horn, 2013), as well as facilitate abstinence from substance use, for example in tobacco addiction (Westbrook et al., 2013).

For instance, to explore how mindfulness might mitigate addiction and craving, Westbrook and colleagues (2013) trained 47 smokers in mindfulness meditation and then had them view smoking-related images designed to induce craving for tobacco. The 
smokers were instructed to either view the images as they normally would, or to practice mindfulness (i.e., maintain a non-judgmental and present-focused attitude) while watching the images, and brain activity during the two conditions was compared. They found that during the mindfulness condition, smokers reported reduced cravings for tobacco, as well as reduced activation in the subgenual anterior cingulate cortex, a brain region widely implicated in craving and addiction for many substances. Functional connectivity between the subgenual anterior cingulate cortex and other brain regions was also reduced in the mindfulness condition, suggesting that meditation practice can have widespread effects on the interactions among multiple brain systems (Westbrook et al., 2013). Clearly, further research into the brain basis of meditation in these and other clinical conditions will be an increasingly important area of study in the future (see further discussion below, in the concluding section). 


\section{Conclusions and future directions}

The growing interest in meditation as both a topic of scientific investigation as well as a means of clinical intervention is long overdue. Nonetheless, this new excitement has to be tempered by the recognition that the research conducted to date has many limitations, as well as the acknowledgment that clinical benefit is far from an established fact, but largely remains to be demonstrated in future, more rigorous research. In this final section, we highlight what the neuroscience of meditation has achieved so far; the caveats that should accompany any interpretation of research to date; and the challenges on the horizon for future studies in both ailing and healthy brains.

\section{What have we learned?}

Cognitive and clinical neuroscientists have mapped out a preliminary understanding of how meditation relates to altered brain structure and function over the past two decades (Figs. 1 and 2). We can say with some confidence that meditation training might alter brain structure (K.C.R. Fox et al., 2014), providing some of the first compelling evidence that purely mental practices can alter brain structure in the same way that cognitive and motor practice appear to (Zatorre et al., 2012). Functional neuroimaging and EEG are providing mounting evidence that meditation alters perceptual, cognitive, and emotional reactions to stimuli and tasks; that different styles of meditation can be differentiated at the neural level (Fig. 2); and that long-term practitioners' attentional stability and introspective aptitude can be harnessed to explore subtle neurocognitive phenomena, such as the arising of spontaneous thoughts (Ellamil et al., 2016). 
Although considerable progress has been made, much remains to be done, particularly in the realm of applied clinical interventions. Researchers are now moving toward understanding the neural mechanisms of meditation's effects on neuropsychiatric conditions as well as natural aging and cognitive decline, but the effectiveness of such interventions, as well as how best to target specific styles of practice to specific clinical conditions, remain challenging but exciting tasks for future research (see below).

\section{Recognizing the limitations of present research}

As should be clear by now, the neuroscience of meditation is a nascent field and agreement among studies and researchers is still the exception rather than the rule. It is risky to generalize findings based on studies with few participants and assume that this holds for anyone and everyone practicing meditation. Very few studies have even acknowledged, much less controlled for, the many factors that might differ between meditation practitioners and control participants, such as diet, stress, sleep patterns, and so on. It also seems clear that pre-existing differences in personality and temperament will predispose certain individuals toward persisting in, and benefitting from, contemplative practices, and there is already tentative evidence that these predispositions might have a brain basis (Mascaro et al., 2013). Publication bias (the preferential publication of only positive results) does not appear to be much of a problem in studies of the psychological and emotional effects of meditation (Sedlmeier et al., 2012), but seems to be a serious issue in morphometric neuroimaging of meditation (K.C.R. Fox et al., 2014). Finally, even when a certain finding is repeatedly replicated, this does not mean that all researchers agree on the interpretation of that result's meaning. For instance, structural and functional changes in 
the insula have now been reported in dozens of studies of the brain basis of meditation (Figs. 1 and 2); the standard interpretation is that these alterations are somehow related to changes in body awareness, but the insula is a highly variable structure implicated in countless other processes besides simply interoception (Butti \& Hof, 2010; Menon \& Uddin, 2010). If and when neuroscientists and clinicians do arrive at a consensus about how meditation interacts with and alters structure and function in both healthy and diseased brains, the meaning of these alterations will still be open to interpretation and, no doubt, fiercely debated.

\section{Clinical horizons}

The use of meditation as an intervention or preventive measure is growing rapidly in many medical fields (Ludwig \& Kabat-Zinn, 2008), and so developing a better understanding of the brain basis of any putative benefits is an important task on the immediate horizon. Neuropsychiatric diseases often show widely differing abnormalities in brain structure and function (Etkin \& Wager, 2007; Hamilton et al., 2012; Valera, Faraone, Murray, \& Seidman, 2007), yet can also share broad impairments that cross diagnostic boundaries, such as dysfunctions of prefrontal brain regions and cognitive control (Etkin, Gyurak, \& O'Hara, 2013). Similarly, while the various methods of meditation also differ widely in their goals and their neural correlates, there are certain commonalities in both psychological experience and neural recruitment across techniques (Fig. 2). With the growing recognition by the scientific and clinical community that there are many techniques beyond the well-known mindfulness meditation, increasing opportunities are opening up for targeting specific styles of meditation for specific neuropsychiatric 
conditions. Early efforts have already been made, for instance using focused attention mantra meditation to treat attention-deficit/hyperactivity disorder (Travis, Sarina, \& Stixrud, 2011) or mindfulness (open monitoring) practices for anxiety (Goldin, Ramel, \& Gross, 2009; Hölzel et al., 2013), but this will likely prove to be a long process of trial and error. Much more effort needs to be dedicated to exploring how various forms of meditation can differentially impact particular neuropsychiatric disorders (K.C.R. Fox, Dixon, et al., 2016; Hofmann, Grossman, \& Hinton, 2011).

\section{Conclusion}

Meditation, practiced in many different forms for thousands of years around the world, has recently given rise to a burgeoning field of scientific study. Neuroscientific methods are teaching us an enormous amount about how the brain generates and sustains contemplative states; long-term, understanding of neural correlates should help us better understand who will adhere to, and benefit most from, meditation practice (Mascaro et al., 2013), as well as aid us in targeting specific contemplative practices for particular neuropsychiatric conditions. But this is not a one-way street: experienced practitioners are already being employed to help neuroscientists understand subtle perceptual and cognitive phenomena that ordinary people rarely notice (Ellamil et al., 2016; K.C.R. Fox et al., 2012), and long-term meditators continue to stretch scientists' conceptions of the brain's limitations when it comes to both unusual cognitive abilities like visualization (Kozhevnikov, Louchakova, Josipovic, \& Motes, 2009) and voluntary control over the peripheral nervous system (Amihai \& Kozhevnikov, 2015; Kox et al., 2012; Kox et al., 2014; Kozhevnikov, Elliott, Shephard, \& Gramann, 2013). Ultimately, the neuroscience of 
meditation promises to shed light on the highest capabilities of the human nervous system and the biological basis of the farther reaches of human spiritual experience (Davis \& Vago, 2013). The past few decades of work have set the stage for future research to develop a rigorous and thorough understanding of how the brain instantiates and is altered by this uniquely human practice. 


\section{References}

Amihai, I., \& Kozhevnikov, M. (2015). The influence of Buddhist meditation traditions on the autonomic system and attention. BioMed research international, 2015.

Andresen, J. (2000). Meditation meets behavioural medicine. The story of experimental research on meditation. Journal of Consciousness Studies, 7(11-12), 17-74.

Badawi, K., Wallace, R., Orme-Johnson, D., \& Rouzere, A. (1984). Electrophysiologic characteristics of respiratory suspension periods occurring during the practice of the Transcendental Meditation Program. Psychosom Med 1984 May-Jun; 46 (3): 267-76. Psychosom Med, 46(3), 267-276.

Bagchi, B., \& Wenger, M. (1957). Electrophysiological correlates of some yogi exercises. Electroencephalography and clinical neurophysiology, 7, 132-149.

Berkovich-Ohana, A., Dor-Ziderman, Y., Glicksohn, J., \& Goldstein, A. (2013). Alterations in the sense of time, space, and body in the mindfulness-trained brain: a neurophenomenologically-guided MEG study. Frontiers in Psychology, 4.

Berkovich-Ohana, A., Glicksohn, J., \& Goldstein, A. (2012). Mindfulness-induced changes in gamma band activity-implications for the default mode network, self-reference and attention. Clinical neurophysiology, 123(4), 700-710.

Berman, A. E., \& Stevens, L. (2015). EEG manifestations of nondual experiences in meditators. Conscious Cogn, 31, 1-11.

Bornemann, B., \& Singer, T. (2017). Taking time to feel our body: Steady increases in heartbeat perception accuracy and decreases in alexithymia over 9 months of contemplative mental training. Psychophysiology, 54(3), 469-482.

Bostanov, V., Keune, P. M., Kotchoubey, B., \& Hautzinger, M. (2012). Event-related brain potentials reflect increased concentration ability after mindfulness-based cognitive therapy for depression: a randomized clinical trial. Psychiatry research, 199(3), 174180.

Braboszcz, C., Cahn, B. R., Levy, J., Fernandez, M., \& Delorme, A. (2017). Increased Gamma Brainwave Amplitude Compared to Control in Three Different Meditation Traditions. PLoS ONE, 12(1), e0170647.

Brandmeyer, T., \& Delorme, A. (2016). Reduced mind wandering in experienced meditators and associated EEG correlates. Experimental brain research, 1-10.

Buckner, R. L., Snyder, A. Z., Shannon, B. J., LaRossa, G., Sachs, R., Fotenos, A. F., ... Morris, J. C. (2005). Molecular, structural, and functional characterization of Alzheimer's disease: evidence for a relationship between default activity, amyloid, and memory. Journal of Neuroscience, 25(34), 7709-7717.

Butti, C., \& Hof, P. R. (2010). The insular cortex: a comparative perspective. Brain Struct Funct, 214(5-6), 477-493. doi:10.1007/s00429-010-0264-y

Buzsaki, G. (2006). Rhythms of the Brain: Oxford University Press.

Cahn, B. R., Delorme, A., \& Polich, J. (2010). Occipital gamma activation during Vipassana meditation. Cognitive processing, 11(1), 39-56.

Cahn, B. R., \& Polich, J. (2006). Meditation states and traits: EEG, ERP, and neuroimaging studies. Psychol Bull, 132(2), 180-211. doi:10.1037/0033-2909.132.2.180

Caroni, P., Chowdhury, A., \& Lahr, M. (2014). Synapse rearrangements upon learning: from divergent-sparse connectivity to dedicated sub-circuits. Trends in Neurosciences, 37(10), 604-614. 
Chen, F., Lv, X., Fang, J., Yu, S., Sui, J., Fan, L., ... Wang, W. (2015). The effect of body-mind relaxation meditation induction on major depressive disorder: A resting-state fMRI study. Journal of affective disorders, 183, 75-82.

Chételat, G., Landeau, B., Salmon, E., Yakushev, I., Bahri, M. A., Mézenge, F., ... Scheurich, A. (2013). Relationships between brain metabolism decrease in normal aging and changes in structural and functional connectivity. Neuroimage, 76, 167-177.

Chételat, G., Mézenge, F., Tomadesso, C., Landeau, B., Arenaza-Urquijo, E., Rauchs, G., ... Gonneaud, J. (2017). Reduced age-associated brain changes in expert meditators: a multimodal neuroimaging pilot study. Scientific Reports, 7(1), 10160.

Christie, G. J., Hamilton, T., Manor, B. D., Farb, N. A., Farzan, F., Sixsmith, A., . . Moreno, S. (2017). Do Lifestyle Activities Protect Against Cognitive Decline in Aging? A Review. Frontiers in Aging Neuroscience, 9, 381.

Christoff, K. (2012). Undirected thought: neural determinants and correlates. Brain Res, 1428, 51-59. doi:10.1016/j.brainres.2011.09.060

Christoff, K., \& Gabrieli, J. D. E. (2000). The frontopolar cortex and human cognition: Evidence for a rostrocaudal hierarchical organization within the human prefrontal cortex. Psychobiology, 28(2), 168-186.

Christoff, K., Gordon, A. M., Smallwood, J., Smith, R., \& Schooler, J. W. (2009). Experience sampling during fMRI reveals default network and executive system contributions to mind wandering. Proc Natl Acad Sci U S A, 106(21), 8719-8724. doi:10.1073/pnas.0900234106

Christoff, K., Gordon, A. M., \& Smith, R. (2011). The role of spontaneous thought in human cognition. In O. Vartanian \& D. R. Mandel (Eds.), Neuroscience of Decision Making (pp. 259-284). New York: Psychology Press.

Christoff, K., Irving, Z. C., Fox, K. C. R., Spreng, R. N., \& Andrews-Hanna, J. R. (2016). Mindwandering as spontaneous thought: A dynamic framework. Nature Reviews Neuroscience, 17, 718-731.

Christoff, K., Ream, J. M., \& Gabrieli, J. D. E. (2004). Neural basis of spontaneous thought processes. Cortex, 40, 623-630.

Craig, A. (2002). How do you feel? Interoception: the sense of the physiological condition of the body. Nature Reviews Neuroscience, 3(8), 655-666.

Craig, A. (2004). Human feelings: why are some more aware than others? Trends in Cognitive Sciences, 8(6), 239-241.

Craig, A. (2009). How do you feel-now? the anterior insula and human awareness. Nature Reviews Neuroscience, $10(1)$.

Critchley, H. D., Wiens, S., Rotshtein, P., Öhman, A., \& Dolan, R. J. (2004). Neural systems supporting interoceptive awareness. Nature Neuroscience, 7(2), 189-195.

Das, N., \& Gastaut, H. (1955). Variations de l'activite electrique du cerveau, du coeur et des muscles squelettiques au cours de la meditation et de l'extase yogique. Electroencephalogrophy and Clinical Neurophysiology. Supplement, 6, 211-219.

Davidson, J. M. (1976). The physiology of meditation and mystical states of consciousness. Perspectives in biology and medicine, 19(3), 345-380.

Davis, J. H., \& Vago, D. R. (2013). Can enlightenment be traced to specific neural correlates, cognition, or behavior? No, and (a qualified) Yes. Frontiers in Psychology, 4. 
DeLosAngeles, D., Williams, G., Burston, J., Fitzgibbon, S. P., Lewis, T. W., Grummett, T. S., .. . Willoughby, J. 0. (2016). Electroencephalographic correlates of states of concentrative meditation. International Journal of Psychophysiology, 110, 27-39.

Dentico, D., Ferrarelli, F., Riedner, B. A., Smith, R., Zennig, C., Lutz, A., .. . Davidson, R. J. (2016). Short meditation trainings enhance non-REM sleep low-frequency oscillations. PLoS ONE, 11(2), e0148961.

Dixon, M. L., Fox, K. C. R., \& Christoff, K. (2014). A framework for understanding the relationship between externally and internally directed cognition. Neuropsychologia, 62, 321-330.

Dor-Ziderman, Y., Ataria, Y., Fulder, S., Goldstein, A., \& Berkovich-Ohana, A. (2016). Selfspecific processing in the meditating brain: a MEG neurophenomenology study. Neuroscience of Consciousness, 2016(1), niw019.

Dor-Ziderman, Y., Berkovich-Ohana, A., Glicksohn, J., \& Goldstein, A. (2013). Mindfulnessinduced selflessness: a MEG neurophenomenological study. Frontiers in Human Neuroscience, 7.

Draganski, B., \& May, A. (2008). Training-induced structural changes in the adult human brain. Behav Brain Res, 192(1), 137-142. doi:10.1016/j.bbr.2008.02.015

Egger, M., Smith, G. D., Schneider, M., \& Minder, C. (1997). Bias in meta-analysis detected by a simple, graphical test. Bmj, 315(7109), 629-634.

Eliade, M. (1964). Shamanism: Archaic techniques of ecstasy: Routledge \& Kegan Paul London.

Ellamil, M., Fox, K. C. R., Dixon, M. L., Pritchard, S., Todd, R. M., Thompson, E., \& Christoff, K. (2016). Dynamics of neural recruitment surrounding the spontaneous arising of thoughts in experienced mindfulness practitioners. Neuroimage, 136, 186-196.

Etkin, A., Gyurak, A., \& O'Hara, R. (2013). A neurobiological approach to the cognitive deficits of psychiatric disorders. Dialogues in clinical neuroscience, 15(4), 419.

Etkin, A., \& Wager, T. D. (2007). Functional neuroimaging of anxiety: a meta-analysis of emotional processing in PTSD, social anxiety disorder, and specific phobia. American Journal of Psychiatry.

Faber, P. L., Lehmann, D., Gianotti, L. R., Milz, P., Pascual-Marqui, R. D., Held, M., \& Kochi, K. (2015). Zazen meditation and no-task resting EEG compared with LORETA intracortical source localization. Cognitive processing, 16(1), 87-96.

Farb, N. A. S., Anderson, A. K., Mayberg, H., Bean, J., McKeon, D., \& Segal, Z. V. (2010). Minding one's emotions: mindfulness training alters the neural expression of sadness. Emotion, 10(1), 25.

Farb, N. A. S., Segal, Z. V., \& Anderson, A. K. (2013). Mindfulness meditation training alters cortical representations of interoceptive attention. Soc Cogn Affect Neurosci, 8(1), 15-26. doi:10.1093/scan/nss066

Farb, N. A. S., Segal, Z. V., Mayberg, H., Bean, J., McKeon, D., Fatima, Z., \& Anderson, A. K. (2007). Attending to the present: mindfulness meditation reveals distinct neural modes of self-reference. Soc Cogn Affect Neurosci, 2(4), 313-322. doi:10.1093/scan/nsm030

Farrow, J. T., \& Hebert, R. J. (1982). Breath suspension during the transcendental meditation technique. Psychosomatic Medicine, 44(2), 133-153.

Fazelpour, S., \& Thompson, E. (2015). The Kantian brain: brain dynamics from a neurophenomenological perspective. Current opinion in neurobiology, 31, 223-229. 
Fenwick, P. (1987). Meditation and the EEG.

Ferrarelli, F., Smith, R., Dentico, D., Riedner, B. A., Zennig, C., Benca, R. M., ... Tononi, G. (2013). Experienced mindfulness meditators exhibit higher parietal-occipital EEG gamma activity during NREM sleep. PLoS ONE, 8(8), e73417.

Fjell, A. M., \& Walhovd, K. B. (2010). Structural brain changes in aging: courses, causes and cognitive consequences. Reviews in the Neurosciences, 21(3), 187-222.

Fleming, S. M., \& Dolan, R. J. (2012). The neural basis of metacognitive ability. Philos Trans $R$ Soc Lond B Biol Sci, 367(1594), 1338-1349. doi:10.1098/rstb.2011.0417

Fleming, S. M., Ryu, J., Golfinos, J. G., \& Blackmon, K. E. (2014). Domain-specific impairment in metacognitive accuracy following anterior prefrontal lesions. Brain, 137(10), 2811-2822.

Fleming, S. M., Weil, R. S., Nagy, Z., Dolan, R. J., \& Rees, G. (2010). Relating introspective accuracy to individual differences in brain structure. Science, 329(5998), 1541-1543. doi:10.1126/science.1191883

Fox, K. C. R., Andrews-Hanna, J. R., \& Christoff, K. (2016). The neurobiology of selfgenerated thought from cells to systems: Integrating evidence from lesion studies, human intracranial electrophysiology, neurochemistry, and neuroendocrinology. Neuroscience, 335, 134-150.

Fox, K. C. R., Andrews-Hanna, J. R., Mills, C., Dixon, M. L., Markovic, J., Thompson, E., \& Christoff, K. (2018). Affective neuroscience of self-generated thought. Annals of the New York Academy of Sciences, Special Issue: The Year in Cognitive Neuroscience.

Fox, K. C. R., \& Christoff, K. (2014). Metacognitive Facilitation of Spontaneous Thought Processes: When Metacognition Helps the Wandering Mind Find Its Way The Cognitive Neuroscience of Metacognition (pp. 293-319): Springer.

Fox, K. C. R., \& Christoff, K. (2018). The Oxford Handbook of Spontaneous Thought: Mindwandering, Creativity, and Dreaming. New York: Oxford University Press.

Fox, K. C. R., Dixon, M. L., Nijeboer, S., Girn, M., Floman, J. L., Lifshitz, M., . . Christoff, K. (2016). Functional neuroanatomy of meditation: A review and meta-analysis of 78 functional neuroimaging investigations. Neurosci Biobehav Rev, 65, 208-228.

Fox, K. C. R., Foster, B. L., Kucyi, A., Daitch, A. L., \& Parvizi, J. (2018). Intracranial electrophysiology of the human default network. Trends in Cognitive Sciences, 22(4), 307-324.

Fox, K. C. R., Nijeboer, S., Dixon, M. L., Floman, J. L., Ellamil, M., Rumak, S. P., . . Christoff, K. (2014). Is meditation associated with altered brain structure? A systematic review and meta-analysis of morphometric neuroimaging in meditation practitioners. Neuroscience \& Biobehavioral Reviews, 43, 48-73.

Fox, K. C. R., Spreng, R. N., Ellamil, M., Andrews-Hanna, J. R., \& Christoff, K. (2015). The wandering brain: Meta-analysis of functional neuroimaging studies of mindwandering and related spontaneous thought processes. Neuroimage, 111, 611-621.

Fox, K. C. R., Zakarauskas, P., Dixon, M. L., Ellamil, M., Thompson, E., \& Christoff, K. (2012). Meditation experience predicts introspective accuracy. PLOS ONE, 7(9), e45370. doi:10.1371/journal.pone.0045370.t001

Fox, N., Scahill, R., Crum, W., \& Rossor, M. (1999). Correlation between rates of brain atrophy and cognitive decline in AD. Neurology, 52(8), 1687-1687.

Fries, P. (2009). Neuronal gamma-band synchronization as a fundamental process in cortical computation. Annual Review of Neuroscience, 32, 209-224. 
Gard, T., Hölzel, B. K., \& Lazar, S. W. (2014). The potential effects of meditation on age related cognitive decline: a systematic review. Annals of the New York Academy of Sciences, 1307(1), 89-103.

Gaser, C., \& Schlaug, G. (2003). Gray matter differences between musicians and nonmusicians. Annals of the New York Academy of Sciences, 999(1), 514-517.

Goenka, S. N. (2000). The discourse summaries: Pariyatti.

Goldin, P. R., \& Gross, J. J. (2010). Effects of mindfulness-based stress reduction (MBSR) on emotion regulation in social anxiety disorder. Emotion, 10(1), 83-91. doi:10.1037/a0018441

Goldin, P. R., Ramel, W., \& Gross, J. (2009). Mindfulness meditation training and selfreferential processing in social anxiety disorder: Behavioral and neural effects. Journal of Cognitive Psychotherapy, 23(3), 242.

Goldin, P. R., Ziv, M., Jazaieri, H., \& Gross, J. J. (2012). Randomized controlled trial of mindfulness-based stress reduction versus aerobic exercise: effects on the selfreferential brain network in social anxiety disorder. Frontiers in Human Neuroscience, 6.

Goldin, P. R., Ziv, M., Jazaieri, H., Hahn, K., \& Gross, J. J. (2013). MBSR vs aerobic exercise in social anxiety: fMRI of emotion regulation of negative self-beliefs. Soc Cogn Affect Neurosci, 8(1), 65-72. doi:10.1093/scan/nss054

Grant, J. A. (2014). Meditative analgesia: the current state of the field. Annals of the New York Academy of Sciences, 1307(1), 55-63.

Grant, J. A., Courtemanche, J., Duerden, E. G., Duncan, G. H., \& Rainville, P. (2010). Cortical thickness and pain sensitivity in zen meditators. Emotion, 10(1), 43-53. doi:10.1037/a0018334

Grant, J. A., Courtemanche, J., \& Rainville, P. (2011). A non-elaborative mental stance and decoupling of executive and pain-related cortices predicts low pain sensitivity in Zen meditators. Pain, 152(1), 150-156. doi:10.1016/j.pain.2010.10.006

Grant, J. A., \& Rainville, P. (2009). Pain sensitivity and analgesic effects of mindful states in Zen meditators: a cross-sectional study. Psychosomatic Medicine, 71(1), 106-114.

Hagerty, M. R., Isaacs, J., Brasington, L., Shupe, L., Fetz, E. E., \& Cramer, S. C. (2013). Case study of ecstatic meditation: fMRI and EEG evidence of self-stimulating a reward system. Neural Plasticity, 2013.

Hamilton, J. P., Etkin, A., Furman, D. J., Lemus, M. G., Johnson, R. F., \& Gotlib, I. H. (2012). Functional neuroimaging of major depressive disorder: a meta-analysis and new integration of baseline activation and neural response data. American Journal of Psychiatry, 169(7), 693-703.

Hauswald, A., Übelacker, T., Leske, S., \& Weisz, N. (2015). What it means to be Zen: Marked modulations of local and interareal synchronization during open monitoring meditation. Neuroimage, 108, 265-273.

Hinterberger, T., Schmidt, S., Kamei, T., \& Walach, H. (2014). Decreased electrophysiological activity represents the conscious state of emptiness in meditation. Frontiers in Psychology, 5.

Hofmann, S. G., Grossman, P., \& Hinton, D. E. (2011). Loving-kindness and compassion meditation: Potential for psychological interventions. Clinical psychology review, 31(7), 1126-1132. 
Holzel, B. K., Carmody, J., Evans, K. C., Hoge, E. A., Dusek, J. A., Morgan, L., . . Lazar, S. W. (2010). Stress reduction correlates with structural changes in the amygdala. Soc Cogn Affect Neurosci, 5(1), 11-17. doi:10.1093/scan/nsp034

Holzel, B. K., Carmody, J., Vangel, M., Congleton, C., Yerramsetti, S. M., Gard, T., \& Lazar, S. W. (2011). Mindfulness practice leads to increases in regional brain gray matter density. Psychiatry Res, 191(1), 36-43. doi:10.1016/j.pscychresns.2010.08.006

Hölzel, B. K., Hoge, E. A., Greve, D. N., Gard, T., Creswell, J. D., Brown, K. W., . . Lazar, S. W. (2013). Neural mechanisms of symptom improvements in generalized anxiety disorder following mindfulness training. NeuroImage: Clinical, 2, 448-458.

Hove, M. J., Stelzer, J., Nierhaus, T., Thiel, S. D., Gundlach, C., Margulies, D. S., . . Merker, B. (2015). Brain network reconfiguration and perceptual decoupling during an absorptive state of consciousness. Cerebral Cortex, 26(7), 3116-3124.

Ives-Deliperi, V. L., Howells, F., Stein, D. J., Meintjes, E. M., \& Horn, N. (2013). The effects of mindfulness-based cognitive therapy in patients with bipolar disorder: a controlled functional MRI investigation. Journal of affective disorders, 150(3), 1152-1157.

Jo, H.-G., Hinterberger, T., Wittmann, M., \& Schmidt, S. (2015). Do meditators have higher awareness of their intentions to act? Cortex, 65, 149-158.

Johnson, W. L. (1982). Riding the ox home: a history of meditation from Shamanism to science: Rider.

Josipovic, Z. (2014). Neural correlates of nondual awareness in meditation. Annals of the New York Academy of Sciences, 1307(1), 9-18.

Josipovic, Z., Dinstein, I., Weber, J., \& Heeger, D. J. (2011). Influence of meditation on anticorrelated networks in the brain. Front Hum Neurosci, 5, 183. doi:10.3389/fnhum.2011.00183

Kaas, J. H. (1983). What, if anything, is SI? Organization of first somatosensory area of cortex. Physiological Reviews, 63(1), 206-231.

Kakigi, R., Nakata, H., Inui, K., Hiroe, N., Nagata, O., Honda, M., ... Kawakami, M. (2005). Intracerebral pain processing in a Yoga Master who claims not to feel pain during meditation. Eur J Pain, 9(5), 581-589. doi:10.1016/j.ejpain.2004.12.006

Kalyani, B. G., Venkatasubramanian, G., Arasappa, R., Rao, N. P., Kalmady, S. V., Behere, R. V., ... Gangadhar, B. N. (2011). Neurohemodynamic correlates of 'OM' chanting: A pilot functional magnetic resonance imaging study. Int J Yoga, 4(1), 3-6. doi:10.4103/0973-6131.78171

Kasamatsu, A., \& Hirai, T. (1966). An electroencephalographic study on the Zen meditation (Zazen). Psychiatry and Clinical Neurosciences, 20(4), 315-336.

Kasamatsu, A., Okuma, T., Takenaka, S., Koga, E., Ikada, K., \& Sugiyama, H. (1957). The EEG of 'Zen' and 'Yoga' practitioners. Electroencephalography and clinical neurophysiology, 9, 51-52.

Kaye, J. A., Swihart, T., Howieson, D., Dame, A., Moore, M., Karnos, T., ... Sexton, G. (1997). Volume loss of the hippocampus and temporal lobe in healthy elderly persons destined to develop dementia. Neurology, 48(5), 1297-1304.

Kjaer, T. W., Bertelsen, C., Piccini, P., Brooks, D., Alving, J., \& Lou, H. C. (2002). Increased dopamine tone during meditation-induced change of consciousness. Cognitive Brain Research, 13(2), 255-259.

Kox, M., Stoffels, M., Smeekens, S. P., Van Alfen, N., Gomes, M., Eijsvogels, T. M., ... Pickkers, P. (2012). The influence of concentration/meditation on autonomic nervous system 
activity and the innate immune response: a case study. Psychosomatic Medicine, 74(5), 489-494.

Kox, M., van Eijk, L. T., Zwaag, J., van den Wildenberg, J., Sweep, F. C., van der Hoeven, J. G., \& Pickkers, P. (2014). Voluntary activation of the sympathetic nervous system and attenuation of the innate immune response in humans. Proceedings of the National Academy of Sciences, 111(20), 7379-7384.

Kozhevnikov, M., Elliott, J., Shephard, J., \& Gramann, K. (2013). Neurocognitive and somatic components of temperature increases during g-Tummo meditation: legend and reality. PLOS ONE, 8(3), e58244.

Kozhevnikov, M., Louchakova, O., Josipovic, Z., \& Motes, M. A. (2009). The enhancement of visuospatial processing efficiency through Buddhist deity meditation. Psychological Science, 20(5), 645-653.

Kurth, F., Cherbuin, N., \& Luders, E. (2015). Reduced age-related degeneration of the hippocampal subiculum in long-term meditators. Psychiatry Research: Neuroimaging, 232(3), 214-218.

Lazar, S. W., Kerr, C. E., Wasserman, R. H., Gray, J. R., Greve, D. N., Treadway, M. T., ... Benson, H. (2005). Meditation experience is associated with increased cortical thickness. Neuroreport, 16(17), 1893-1897.

Logothetis, N. K., Pauls, J., Augath, M., Trinath, T., \& Oeltermann, A. (2001). Neurophysiological investigation of the basis of the fMRI signal. Nature, 412(6843), 150-157.

Lou, H. C., Kjaer, T. W., Friberg, L., Wildschlodtz, G., Holm, S., \& Nowak, M. (1999). A 150H20 PET study of meditation and the resting state of normal consciousness. Human Brain Mapping, 7, 98-105.

Luders, E., Cherbuin, N., \& Gaser, C. (2016). Estimating brain age using high-resolution pattern recognition: younger brains in long-term meditation practitioners. Neuroimage, 134, 508-513.

Luders, E., Cherbuin, N., Kurth, F., \& Lauche, R. (2015). Forever Young (er): potential agedefying effects of long-term meditation on gray matter atrophy. Frontiers in Psychology, 5.

Ludwig, D. S., \& Kabat-Zinn, J. (2008). Mindfulness in medicine. Jama, 300(11), 1350-1352.

Lutz, A., Greischar, L., Ricard, M., Converse, A., \& Davidson, R. (2003). Comparative study of synchrony patterns during three meditative states: Preliminary data. Abstract Viewer and Itinerary Planner: Abstract, 86.

Lutz, A., Jha, A. P., Dunne, J. D., \& Saron, C. D. (2015). Investigating the phenomenological matrix of mindfulness-related practices from a neurocognitive perspective. American Psychologist, 70(7), 632.

Lutz, A., Slagter, H. A., Dunne, J. D., \& Davidson, R. J. (2008). Attention regulation and monitoring in meditation. Trends Cogn Sci, 12(4), 163-169. doi:10.1016/j.tics.2008.01.005

Lutz, A., \& Thompson, E. (2003). Neurophenomenology: Integrating subjective experience and brain dynamics in the neuroscience of consciousness. Journal of Consciousness Studies, 10(9-10), 31-52.

MacLean, K. A., Ferrer, E., Aichele, S. R., Bridwell, D. A., Zanesco, A. P., Jacobs, T. L., ... Shaver, P. R. (2010). Intensive meditation training improves perceptual discrimination and sustained attention. Psychological Science, 21(6), 829-839. 
Marx, G., \& Gilon, C. (2012). The molecular basis of memory. ACS Chemical Neuroscience, 3(8), 633-642.

Mascaro, J. S., Rilling, J. K., Negi, L. T., \& Raison, C. L. (2013). Pre-existing brain function predicts subsequent practice of mindfulness and compassion meditation. Neuroimage, 69, 35-42. doi:10.1016/j.neuroimage.2012.12.021

May, A., \& Gaser, C. (2006). Magnetic resonance-based morphometry: a window into structural plasticity of the brain. Current opinion in neurology, 19(4), 407-411.

Meltzer, J. A., Negishi, M., Mayes, L. C., \& Constable, R. T. (2007). Individual differences in EEG theta and alpha dynamics during working memory correlate with fMRI responses across subjects. Clinical neurophysiology, 118(11), 2419-2436.

Menon, V., \& Uddin, L. Q. (2010). Saliency, switching, attention and control: a network model of insula function. Brain Structure and Function, 214(5-6), 655-667.

Mrazek, M. D., Franklin, M. S., Phillips, D. T., Baird, B., \& Schooler, J. W. (2013). Mindfulness Training Improves Working Memory Capacity and GRE Performance While Reducing Mind Wandering. Psychological Science, 24(5), 776-781. doi:10.1177/0956797612459659

Mukamel, R., Gelbard, H., Arieli, A., Hasson, U., Fried, I., \& Malach, R. (2005). Coupling between neuronal firing, field potentials, and FMRI in human auditory cortex. Science, 309(5736), 951-954.

Murta, T., Leite, M., Carmichael, D. W., Figueiredo, P., \& Lemieux, L. (2015). Electrophysiological correlates of the BOLD signal for EEG - informed fMRI. Human Brain Mapping, 36(1), 391-414.

Neubauer, R. L. (2014). Prayer as an interpersonal relationship: A neuroimaging study. Religion, Brain \& Behavior, 4(2), 92-103.

Newberg, A., Pourdehnad, M., Alavi, A., \& d'Aquili, E. G. (2003). Cerebral blood flow during meditative prayer: preliminary findings and methodological issues. Perceptual and motor skills, 97(2), 625-630.

Northoff, G., Heinzel, A., de Greck, M., Bermpohl, F., Dobrowolny, H., \& Panksepp, J. (2006). Self-referential processing in our brain-a meta-analysis of imaging studies on the self. Neuroimage, 31(1), 440-457.

Norton, S., Matthews, F. E., Barnes, D. E., Yaffe, K., \& Brayne, C. (2014). Potential for primary prevention of Alzheimer's disease: an analysis of population-based data. The Lancet Neurology, 13(8), 788-794.

Pagnoni, G., \& Cekic, M. (2007). Age effects on gray matter volume and attentional performance in Zen meditation. Neurobiol Aging, 28(10), 1623-1627. doi:10.1016/j.neurobiolaging.2007.06.008

Penfield, W., \& Boldrey, E. (1937). Somatic motor and sensory representation in the cerebral cortex of man as studied by electrical stimulation. Brain, 60, 389-443.

Rahl, H. A., Lindsay, E. K., Pacilio, L. E., Brown, K. W., \& Creswell, J. D. (2017). Brief mindfulness meditation training reduces mind wandering: The critical role of acceptance. Emotion, 17(2), 224.

Rainville, P., Duncan, G. H., Price, D. D., Carrier, B., \& Bushnell, M. C. (1997). Pain affect encoded in human anterior cingulate but not somatosensory cortex. Science, 277(5328), 968-971. 
Ramnani, N., \& Owen, A. M. (2004). Anterior prefrontal cortex: insights into function from anatomy and neuroimaging. Nat Rev Neurosci, 5(3), 184-194. doi:10.1038/nrn1343

Richter, C. G., Thompson, W. H., Bosman, C. A., \& Fries, P. (2017). Top-down beta enhances bottom-up gamma. Journal of Neuroscience, 3771-3716.

Rosenthal, R. (1979). The file drawer problem and tolerance for null results. Psychological Bulletin, 86(3), 638.

Rusinek, H., De Santi, S., Frid, D., Tsui, W.-H., Tarshish, C. Y., Convit, A., \& de Leon, M. J. (2003). Regional brain atrophy rate predicts future cognitive decline: 6-year longitudinal MR imaging study of normal aging. Radiology, 229(3), 691-696.

Saggar, M., King, B. G., Zanesco, A. P., MacLean, K. A., Aichele, S. R., Jacobs, T. L., ... Sahdra, B. K. (2012). Intensive training induces longitudinal changes in meditation staterelated EEG oscillatory activity. Frontiers in Human Neuroscience, 6.

Scheeringa, R., Bastiaansen, M. C., Petersson, K. M., Oostenveld, R., Norris, D. G., \& Hagoort, P. (2008). Frontal theta EEG activity correlates negatively with the default mode network in resting state. International Journal of Psychophysiology, 67(3), 242-251.

Scheeringa, R., Fries, P., Petersson, K.-M., Oostenveld, R., Grothe, I., Norris, D. G., ... Bastiaansen, M. C. (2011). Neuronal dynamics underlying high-and low-frequency EEG oscillations contribute independently to the human BOLD signal. Neuron, 69(3), 572-583.

Scheeringa, R., Koopmans, P. J., van Mourik, T., Jensen, O., \& Norris, D. G. (2016). The relationship between oscillatory EEG activity and the laminar-specific BOLD signal. Proceedings of the National Academy of Sciences, 113(24), 6761-6766.

Schjødt, U., Stødkilde-Jørgensen, H., Geertz, A. W., \& Roepstorff, A. (2008). Rewarding prayers. Neuroscience letters, 443(3), 165-168.

Schneider, P., Scherg, M., Dosch, H. G., Specht, H. J., Gutschalk, A., \& Rupp, A. (2002). Morphology of Heschl's gyrus reflects enhanced activation in the auditory cortex of musicians. Nature Neuroscience, 5(7), 688-694.

Schoenberg, P. L., Hepark, S., Kan, C. C., Barendregt, H. P., Buitelaar, J. K., \& Speckens, A. E. (2014). Effects of mindfulness-based cognitive therapy on neurophysiological correlates of performance monitoring in adult attention-deficit/hyperactivity disorder. Clinical neurophysiology, 125(7), 1407-1416.

Schoenberg, P. L., Ruf, A., Churchill, J., Brown, D. P., \& Brewer, J. A. (2018). Mapping complex mind states: EEG neural substrates of meditative unified compassionate awareness. Conscious Cogn, 57, 41-53.

Schoenberg, P. L., \& Speckens, A. E. (2015). Multi-dimensional modulations of $\alpha$ and $\gamma$ cortical dynamics following mindfulness-based cognitive therapy in Major Depressive Disorder. Cognitive neurodynamics, 9(1), 13-29.

Schuman, M. (1980). The psychophysiological model of meditation and altered states of consciousness: A critical review The psychobiology of consciousness (pp. 333-378): Springer.

Sedlmeier, P., Eberth, J., Schwarz, M., Zimmermann, D., Haarig, F., Jaeger, S., \& Kunze, S. (2012). The Psychological Effects of Meditation: A Meta-Analysis. Psychological Bulletin, 138(6), 1139-1171. doi:10.1037/a0028168.supp

Shapiro, D. H., \& Walsh, R. N. (1984). Meditation: Classic and contemporary perspectives: AldineTransaction. 
Sze, J. A., Gyurak, A., Yuan, J. W., \& Levenson, R. W. (2010). Coherence between emotional experience and physiology: Does body awareness training have an impact? Emotion, 10(6), 803-814. doi:10.1037/a0020146

Tanaka, G. K., Maslahati, T., Gongora, M., Bittencourt, J., Lopez, L. C. S., Demarzo, M. M. P., . . . Campayo, J. G. (2015). Effortless attention as a biomarker for experienced mindfulness practitioners. PLoS ONE, 10(10), e0138561.

Tang, Y.-Y., Hölzel, B. K., \& Posner, M. I. (2015). The neuroscience of mindfulness meditation. Nature Reviews Neuroscience, 16(4), 213-225.

Tang, Y.-Y., Lu, Q., Fan, M., Yang, Y., \& Posner, M. I. (2012). Mechanisms of white matter changes induced by meditation. Proceedings of the National Academy of Sciences, 109(26), 10570-10574.

Tang, Y. Y., Lu, Q., Geng, X., Stein, E. A., Yang, Y., \& Posner, M. I. (2010). Short-term meditation induces white matter changes in the anterior cingulate. Proc Natl Acad Sci U S A, 107(35), 15649-15652. doi:10.1073/pnas.1011043107

Teasdale, J. (1999). Metacognition, mindfulness and the modification of mood disorders. Clinical Psychology \& Psychotherapy, 6(2), 146-155.

Teasdale, J., Moore, R. G., Hayhurst, H., Pope, M., Williams, S., \& Segal, Z. V. (2002). Metacognitive awareness and prevention of relapse in depression: Empirical evidence. Journal of consulting and clinical psychology, 70(2), 275-287. doi:10.1037//0022-006x.70.2.275

Thomas, C., \& Baker, C. I. (2013). Teaching an adult brain new tricks: a critical review of evidence for training-dependent structural plasticity in humans. Neuroimage, 73, 225-236. doi:10.1016/j.neuroimage.2012.03.069

Thompson, E. (2009). Contemplative neuroscience as an approach to volitional consciousness Downward causation and the neurobiology of free will (pp. 187-197): Springer.

Travis, F. (2001). Autonomic and EEG patterns distinguish transcending from other experiences during Transcendental Meditation practice. International Journal of Psychophysiology, 42(1), 1-9.

Travis, F., \& Pearson, C. (2000). Pure consciousness: distinct phenomenological and physiological correlates of "consciousness itself". International Journal of Neuroscience, 100(1-4), 77-89.

Travis, F., Sarina, G., \& Stixrud, W. (2011). ADHD, brain functioning, and transcendental meditation practice. Mind \& Brain, 2(1).

Valera, E. M., Faraone, S. V., Murray, K. E., \& Seidman, L. J. (2007). Meta-analysis of structural imaging findings in attention-deficit/hyperactivity disorder. Biological psychiatry, 61(12), 1361-1369.

Van Dam, N. T., van Vugt, M. K., Vago, D. R., Schmalzl, L., Saron, C. D., Olendzki, A., ... Meyer, D. E. (2018). Reiterated Concerns and Further Challenges for Mindfulness and Meditation Research: A Reply to Davidson and Dahl. Perspectives on Psychological Science, 13(1), 66-69.

Van Dam, N. T., van Vugt, M. K., Vago, D. R., Schmalzl, L., Saron, C. D., Olendzki, A., . . Meyer, D. E. (2018). Mind the hype: A critical evaluation and prescriptive agenda for research on mindfulness and meditation. Perspectives on Psychological Science, 13(1), 36-61. 
van Ede, F., de Lange, F., Jensen, O., \& Maris, E. (2011). Orienting attention to an upcoming tactile event involves a spatially and temporally specific modulation of sensorimotor alpha-and beta-band oscillations. Journal of Neuroscience, 31(6), 2016-2024.

Varela, F. J. (1996). Neurophenomenology: A methodological remedy for the hard problem. Journal of Consciousness Studies, 3(4), 330-349.

Wager, T. D., Lindquist, M., \& Kaplan, L. (2007). Meta-analysis of functional neuroimaging data: current and future directions. Soc Cogn Affect Neurosci, 2(2), 150-158. doi:10.1093/scan/nsm015

Wager, T. D., Lindquist, M. A., Nichols, T. E., Kober, H., \& Van Snellenberg, J. X. (2009). Evaluating the consistency and specificity of neuroimaging data using meta-analysis. Neuroimage, 45(1 Suppl), S210-221. doi:10.1016/j.neuroimage.2008.10.061

Wells, R. E., Yeh, G. Y., Kerr, C. E., Wolkin, J., Davis, R. B., Tan, Y., . . Kaptchuk, T. J. (2013). Meditation's impact on default mode network and hippocampus in mild cognitive impairment: a pilot study. Neuroscience letters, 556, 15-19.

West, M. A. (1980). Meditation and the EEG. Psychological medicine, 10(2), 369-375.

Westbrook, C., Creswell, J. D., Tabibnia, G., Julson, E., Kober, H., \& Tindle, H. A. (2013). Mindful attention reduces neural and self-reported cue-induced craving in smokers. Soc Cogn Affect Neurosci, 8(1), 73-84. doi:10.1093/scan/nsr076

Wynne, A. (2007). The origin of Buddhist meditation: routledge.

Yarkoni, T., Poldrack, R. A., Van Essen, D. C., \& Wager, T. D. (2010). Cognitive neuroscience 2.0: building a cumulative science of human brain function. Trends Cogn Sci, 14(11), 489-496. doi:10.1016/j.tics.2010.08.004

Zanesco, A. P., King, B. G., MacLean, K. A., Jacobs, T. L., Aichele, S. R., Wallace, B. A., ... Saron, C. D. (2016). Meditation training influences mind wandering and mindless reading. Psychology of Consciousness: Theory, Research, and Practice, 3(1), 12.

Zatorre, R. J., Fields, R. D., \& Johansen-Berg, H. (2012). Plasticity in gray and white: neuroimaging changes in brain structure during learning. Nat Neurosci, 15(4), 528536. doi:10.1038/nn.3045

Zeidan, F., Adler-Neal, A. L., Wells, R. E., Stagnaro, E., May, L. M., Eisenach, J. C., ... Coghill, R. C. (2016). Mindfulness-meditation-based pain relief is not mediated by endogenous opioids. Journal of Neuroscience, 36(11), 3391-3397.

Zeidan, F., Emerson, N. M., Farris, S. R., Ray, J. N., Jung, Y., McHaffie, J. G., \& Coghill, R. C. (2015). Mindfulness meditation-based pain relief employs different neural mechanisms than placebo and sham mindfulness meditation-induced analgesia. Journal of Neuroscience, 35(46), 15307-15325.

Zeidan, F., Grant, J. A., Brown, C. A., McHaffie, J. G., \& Coghill, R. C. (2012). Mindfulness meditation-related pain relief: evidence for unique brain mechanisms in the regulation of pain. Neurosci Lett, 520(2), 165-173. doi:10.1016/j.neulet.2012.03.082

Zeidan, F., Martucci, K. T., Kraft, R. A., Gordon, N. S., McHaffie, J. G., \& Coghill, R. C. (2011). Brain mechanisms supporting the modulation of pain by mindfulness meditation. $J$ Neurosci, 31(14), 5540-5548. doi:10.1523/JNEUROSCI.5791-10.2011 